\title{
Methyltransferase-like 3 Modulates Severe Acute Respiratory Syndrome Coronavirus-2 RNA N6-Methyladenosine Modification and Replication
}

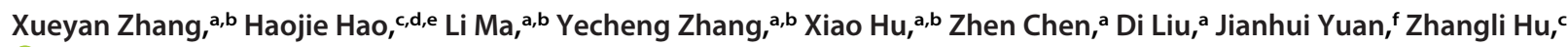 \\ (D) Wuxiang Guan ${ }^{\mathrm{a}}$ \\ aCenter for Emerging Infectious Diseases, Wuhan Institute of Virology, Center for Biosafety Mega-Science, Chinese Academy of Sciences, Wuhan, Hubei, China \\ bUniversity of Chinese Academy of Sciences, Beijing, China \\ cCollege of Life Sciences and Oceanography, Shenzhen University, Shenzhen, China \\ dCollege of Physics and Optoelectronic Engineering, Shenzhen University, Shenzhen, China \\ eHanshan Normal University, Chaozhou, China \\ iNanshan District Center for Disease Control and Prevention, Shenzhen, China
}

ABSTRACT The coronavirus disease 2019 pandemic caused by severe acute respiratory syndrome coronavirus-2 (SARS-CoV-2) is an ongoing global public crisis. Although viral RNA modification has been reported based on the transcriptome architecture, the types and functions of RNA modification are still unknown. In this study, we evaluated the roles of RNA N6-methyladenosine $\left(m^{6} A\right)$ modification in SARS-CoV-2. Our methylated RNA immunoprecipitation sequencing (MeRIP-Seq) and Nanopore direct RNA sequencing (DRS) analysis showed that SARS-CoV-2 RNA contained $\mathrm{m}^{6} \mathrm{~A}$ modification. Moreover, SARS-CoV-2 infection not only increased the expression of methyltransferase-like 3 (METTL3) but also altered its distribution. Modification of METTL3 expression by short hairpin RNA or plasmid transfection for knockdown or overexpression, respectively, affected viral replication. Furthermore, the viral key protein RdRp interacted with METTL3, and METTL3 was distributed in both the nucleus and cytoplasm in the presence of RdRp. RdRp appeared to modulate the sumoylation and ubiquitination of METTL3 via an unknown mechanism. Taken together, our findings demonstrated that the host $\mathrm{m}^{6} \mathrm{~A}$ modification complex interacted with viral proteins to modulate SARS-CoV-2 replication.

IMPORTANCE Internal chemical modifications of viral RNA play key roles in the regulation of viral replication and gene expression. Although potential internal modifications have been reported in SARS-CoV-2 RNA, the function of the SARS-CoV-2 N6-methyladenosine $\left(m^{6} A\right)$ modification in the viral life cycle is unclear. In the current study, we demonstrated that SARS-CoV-2 RNA underwent $\mathrm{m}^{6} \mathrm{~A}$ modification by host $\mathrm{m}^{6} \mathrm{~A}$ machinery. SARS-CoV-2 infection altered the expression pattern of methyltransferases and demethylases, while the expression level of methyltransferase-like 3 (METTL3) and fat mass and obesity-associated protein (FTO) was linked to the viral replication. Further study showed that METTL3 interacted with viral RNA polymerase RNA-dependent RNA polymerase (RdRp), which influenced not only the distribution but also the posttranslational modification of METTL3. Our study provided evidence that host $\mathrm{m}^{6} \mathrm{~A}$ components interacted with viral proteins to modulate viral replication.

KEYWORDS methyltransferase-like 3, respiratory syndrome coronavirus-2, N6-methyladenosine, viral replication

- he coronavirus disease 2019 (COVID-19) pandemic is caused by severe acute respiratory syndrome coronavirus-2 (SARS-CoV-2), which belongs to the genus Betacoronavirus in
Citation Zhang X, Hao H, Ma L, Zhang Y, Hu X, Chen Z, Liu D, Yuan J, Hu Z, Guan W. 2021. Methyltransferase-like 3 modulates severe acute respiratory syndrome coronavirus-2 RNA N6-methyladenosine modification and replication. mBio 12:e01067-21. https://doi.org/ 10.1128/mBio.01067-21

Editor Xiang-Jin Meng, Virginia Polytechnic Institute and State University

Copyright $\odot 2021$ Zhang et al. This is an openaccess article distributed under the terms of the Creative Commons Attribution 4.0 International license. Address correspondence to Wuxiang Guan guanwx@wh.iov.cn

Received 27 April 2021

Accepted 4 June 2021

Published 6 July 2021 
the Coronavirinae subfamily of the Coronaviridae family (1-3). The rapid transmission of COVID-19 has been a major global challenge. Similar to the other two $\beta$-category coronaviruses, SARS-CoV-2 harbors a positive-sense, single-stranded RNA genome of approximately $30 \mathrm{~kb}$, with $80 \%$ and $50 \%$ homology to SARS-CoV and Middle East respiratory syndrome coronavirus (MERS-CoV), respectively (4).

Internal chemical modifications of viral RNA play key roles in the regulation of viral infection. N6-methyladenosine $\left(\mathrm{m}^{6} \mathrm{~A}\right), 5$-methylcytosine $\left(\mathrm{m}^{5} \mathrm{C}\right)$, and N4-acetylcytidine (ac4C) have been reported to be involved in the viral life cycle (5-10). $\mathrm{m}^{6} \mathrm{~A}$ is one of the most abundant internal RNA modifications $(11,12)$. The $\mathrm{m}^{6} \mathrm{~A}$ machinery consists of "writers," "erasers," and "readers." The writers, including methyltransferase-like (METTL) 3, METTL14, WT1-associated protein (WTAP), and other proteins, catalyze the transfer of the $\mathrm{m}^{6} \mathrm{~A}$ modification (13-23). The erasers fat mass and obesity-associated protein (FTO) and AlkB homolog 5 (ALKBH5) are $\mathrm{m}^{6} \mathrm{~A}$ demethylases that remove the methyl groups from RNA (22-25). The readers contain a YT521-B homology (YTH) motif that binds to $\mathrm{m}^{6} \mathrm{~A}$ sites and play critical roles in mRNA stability (26-28), RNA processing (25), RNA structure (29), and translation $(30,31)$.

The internal $\mathrm{m}^{6} \mathrm{~A}$ modification of viral RNA was identified in viruses that replicate in the cytoplasm, such as vesicular stomatitis virus, vaccinia virus, and reovirus, 40 years ago (32-36). However, the function of $\mathrm{m}^{6} \mathrm{~A}$ was only recent elucidated in hepatitis $\mathrm{C}$ virus (HCV), Zika virus (ZIKV), dengue virus, yellow fever virus, and West Nile virus (37, 38). In viruses that replicate in the nucleus, such as human immunodeficiency virus (HIV), simian virus 40, Kaposi's sarcoma-associated herpesvirus, and influenza virus, viral $\mathrm{m}^{6} \mathrm{~A}$ modifications have been shown to affect viral replication and gene expression (39-46). Recent studies have found that $\mathrm{m}^{6} \mathrm{~A}$ is present on SARS virus RNA and affects virus replication $(47,48)$, but the specific molecular mechanism of $m^{6} A$ regulating virus replication is still unclear. At least 41 sites modified on the SARS-CoV-2 genome are potential sites of RNA modification, which is particularly enriched at genomic nucleotide positions 28500 to 29500 (49).

Accordingly, in the current study, we investigated the presence of the roles of $\mathrm{m}^{6} \mathrm{~A}$ modification in SARS-CoV-2 RNA using methylated RNA immunoprecipitation sequencing (MeRIP-Seq) and Nanopore direct RNA sequencing (DRS). Overall, our findings demonstrated that the host $\mathrm{m}^{6} \mathrm{~A}$ modification complex interacted with viral proteins and modulated SARS-CoV-2 replication.

\section{RESULTS}

SARS-CoV-2 infection altered the expression patterns of $\mathrm{m}^{6} \mathrm{~A}$ methyltransferases and demethylases. The $\mathrm{m}^{6} \mathrm{~A}$ methyltransferases and demethylases are mainly localized in the nucleus. Infection by viruses that replicate in the cytoplasm, such as enterovirus 71 (EV71), HCV, ZIKV, and porcine epidemic diarrhea virus (PEDV), affects the expression and localization of methyltransferases and demethylases to facilitate their RNA $m^{6} \mathrm{~A}$ modifications, which influences viral replication $(37,38,50-52)$. To check whether SARS-CoV-2 infection had a similar effect, SARS-CoV-2-infected Vero E6 cells were harvested. The expression of viral $\mathrm{N}$ and $\mathrm{m}^{6} \mathrm{~A}$ machinery proteins was assessed by Western blotting with corresponding antibodies (Fig. 1A). Our results showed that the expression of METTL3 was increased at $48 \mathrm{~h}$ postinfection (hpi), whereas the expression levels of METTL14 and WTAP were not affected (Fig. 1A). The expression of the demethylase FTO decreased at $48 \mathrm{hpi}$, whereas that of ALKBH5 was not changed after infection. Moreover, the expression of the $m^{6} \mathrm{~A}$ binding proteins YTHDF1 to $-3, \mathrm{YTHDC1}$, and YTHDC2 was not altered during SARS-CoV-2 infection (Fig. 1A).

Previous studies have shown that $\mathrm{m}^{6} \mathrm{~A}$ methyltransferases and demethylases colocalize with nuclear speckle markers and that viral infection affects the subcellular localization of $\mathrm{m}^{6} \mathrm{~A}$-related proteins. Because SARS-CoV-2 infection affects the expression of METTL3 and FTO, we next determined the effects of SARS-CoV-2 infection on the localization of methyltransferases and demethylases. Consistent with previous results, methyltransferases and demethylases were detected mostly in the nucleus under normal conditions (Fig. 1B to F). However, METTL3, METTL14, WTAP, ALKBH5, and FTO 
A

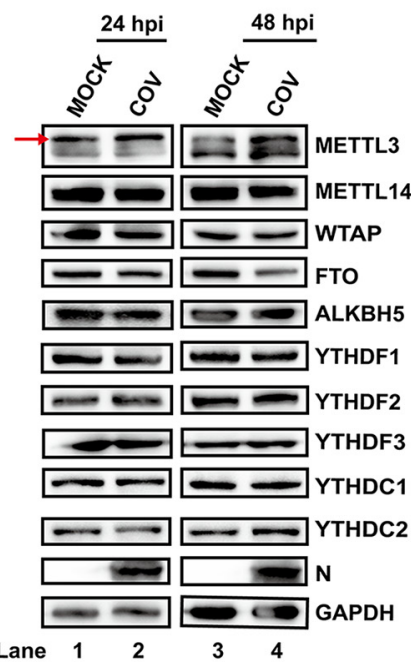

E

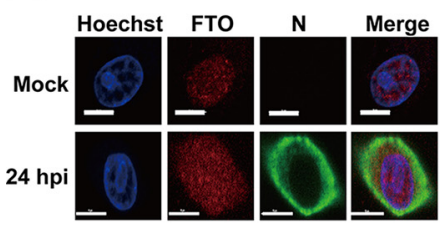

B

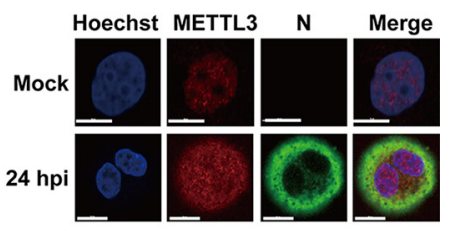

C Hoechst MEtTL14 N Merge

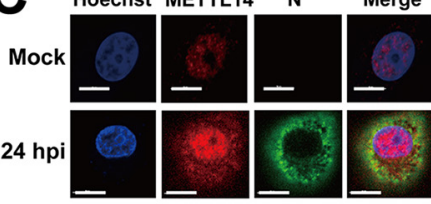

D

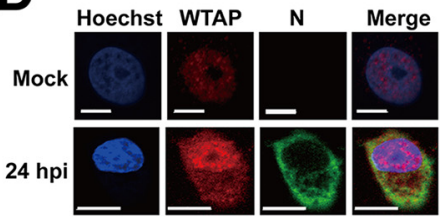

$\mathbf{F}$

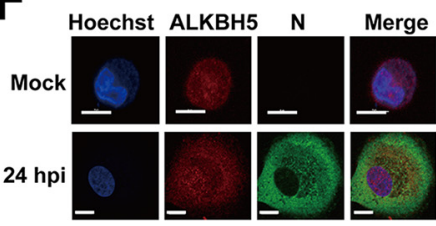

FIG 1 SARS-CoV-2 infection influenced the expression patterns of $m^{6} A$-related proteins. (A) Western blotting. Vero E6 cells infected with SARS-CoV-2 $(\mathrm{MOI}=0.01)$ were harvested at 24 and $48 \mathrm{hpi}$. Western blotting was performed with antibodies as indicated. GAPDH was used as a loading control. The arrow represents the METTL3-specific band. (B to F) Confocal microscopy images of SARS-CoV-2or mock-infected Vero E6 cells. The nucleus (blue) and virus protein N (green) were labeled with Hoechst and anti-N-specific antibodies, respectively. The methyltransferases and demethylases were stained with antibodies as indicated. Scale bars, $5 \mu \mathrm{m}$.

were all present in both the nucleus and cytoplasm after infection (Fig. 1B to F). The colocalization of methyltransferases and demethylases with viral protein $\mathrm{N}$ implied that these proteins may interact with SARS-CoV-2 RNA in the cytoplasm. The abovedescribed results provided evidence that SARS-CoV-2 may be modified by the host $\mathrm{m}^{6} \mathrm{~A}$ machinery.

SARS-CoV-2 RNA contained $\mathbf{m}^{\mathbf{6}} \mathbf{A}$ modifications. To investigate whether SARSCoV-2 RNA was $\mathrm{m}^{6} \mathrm{~A}$ modified, total RNAs were purified from large-scale batches of SARS-CoV-2-infected Vero E6 cells, and MeRIP was then performed with $\mathrm{m}^{6} \mathrm{~A}$-specific antibodies. The MeRIP RNA was subjected to Northern blotting with SARS-CoV-2 probes spanning nucleotides (nt) 28274 to 29870. SARS-CoV-2 RNA was then pulled down using anti- ${ }^{6} \mathrm{~A}$ antibodies (Fig. $2 \mathrm{~A}$ ), indicating that SARS-CoV-2 contained $\mathrm{m}^{6} \mathrm{~A}$ residues. To further confirm the above-described results and map the $m^{6} A$ modification status in the SARS-CoV-2 RNA genome, MeRIP-Seq was performed. Five $\mathrm{m}^{6} \mathrm{~A}$ peaks were identified in the $5^{\prime}$ end (nt 36 to 753 and nt 1023 to 1324) and the $3^{\prime}$ end (nt 27493 to 27913 , nt 28475 to 28706, and nt 28944 to 29751) (Fig. 2B to D), which were located in the ORF1ab-, N-, and ORF10-coding regions (Fig. S1A). These results implied that SARS-CoV-2 RNA was marked by $\mathrm{m}^{6} \mathrm{~A}$ modification during infection. To further confirm the specific $\mathrm{m}^{6} \mathrm{~A}$ modification sites, we performed the nanopore-based direct RNA sequencing (DRS) using a MinION nanopore sequencer with total RNAs extracted from Vero E6, A549-ACE2, and Huh7 cells infected with SARS-CoV-2. Consistent with 
A

B
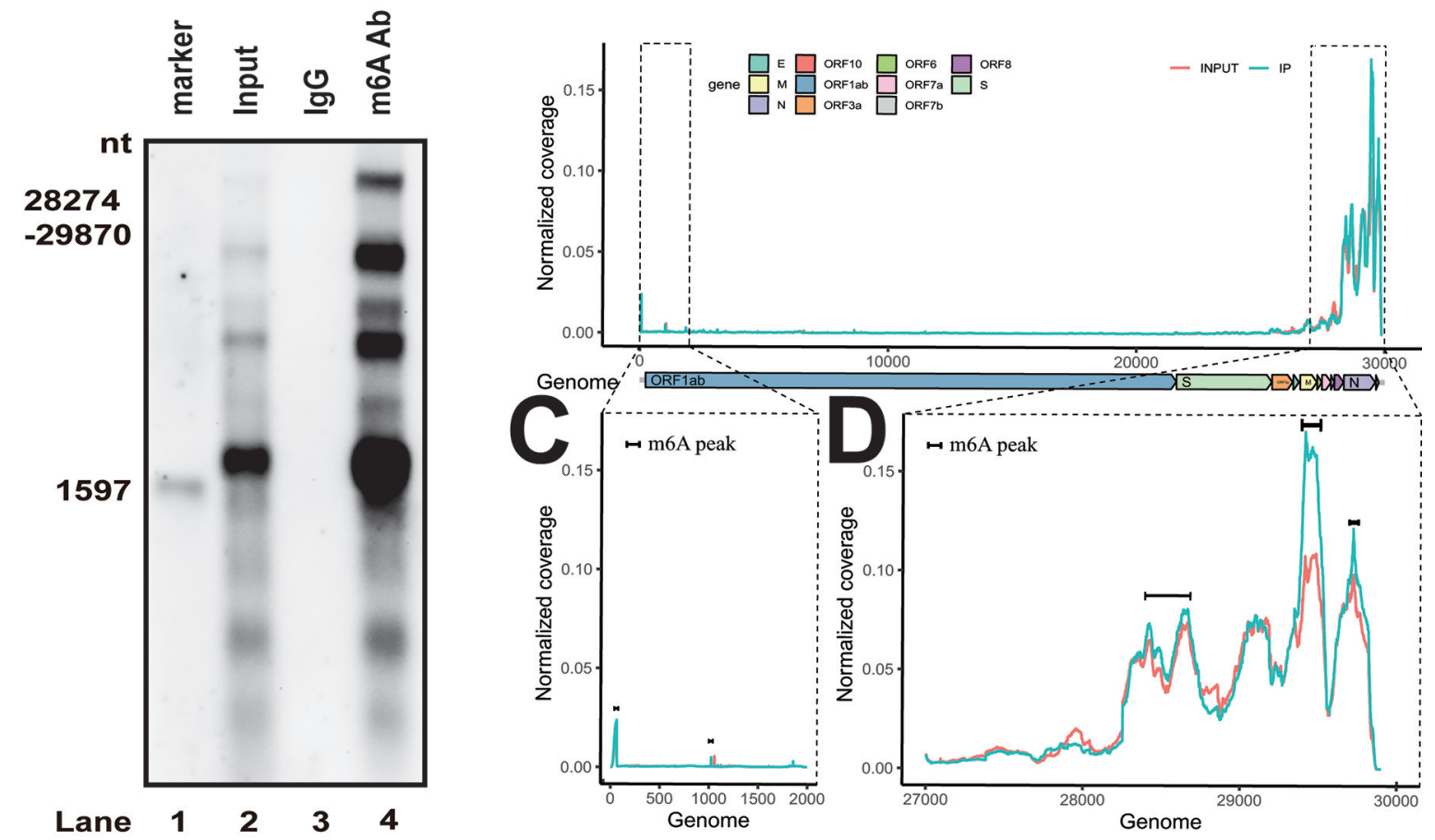

\section{RIP-seq Vero-E6}
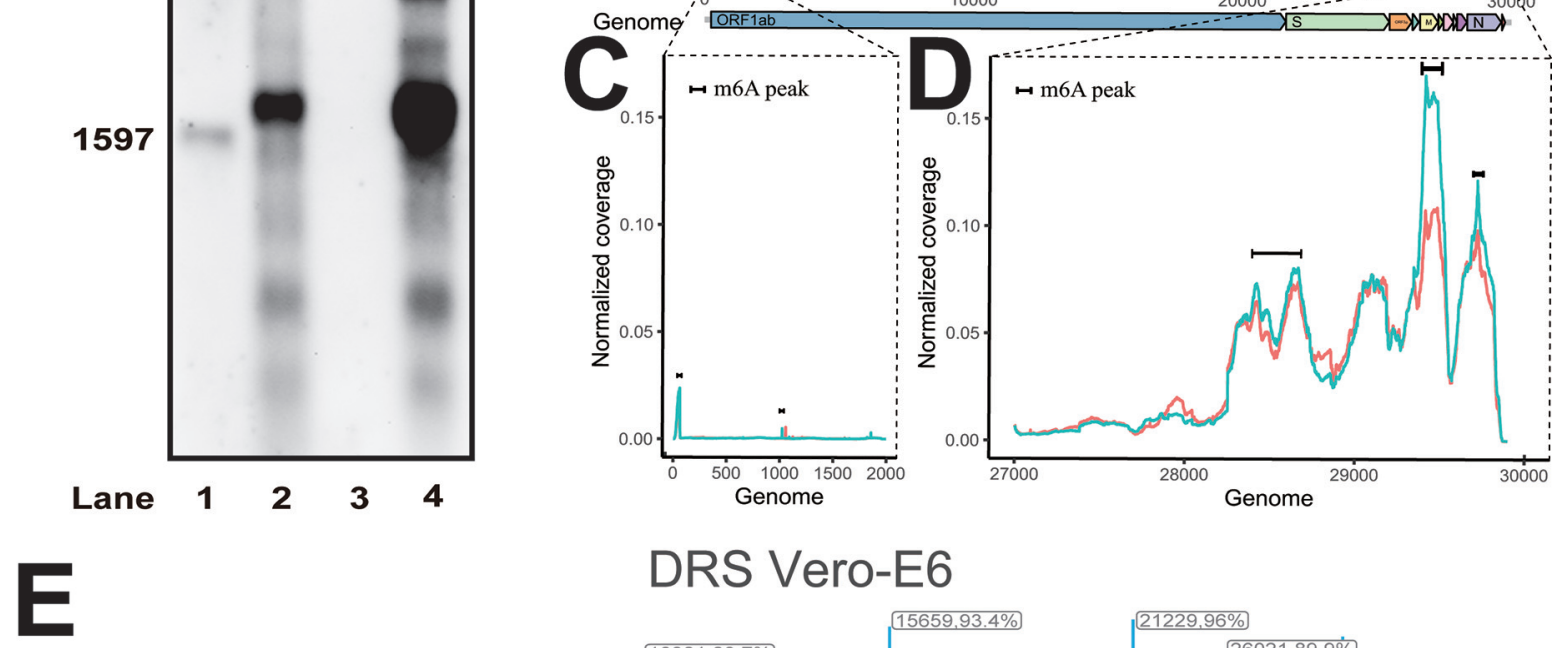

DRS Vero-E6

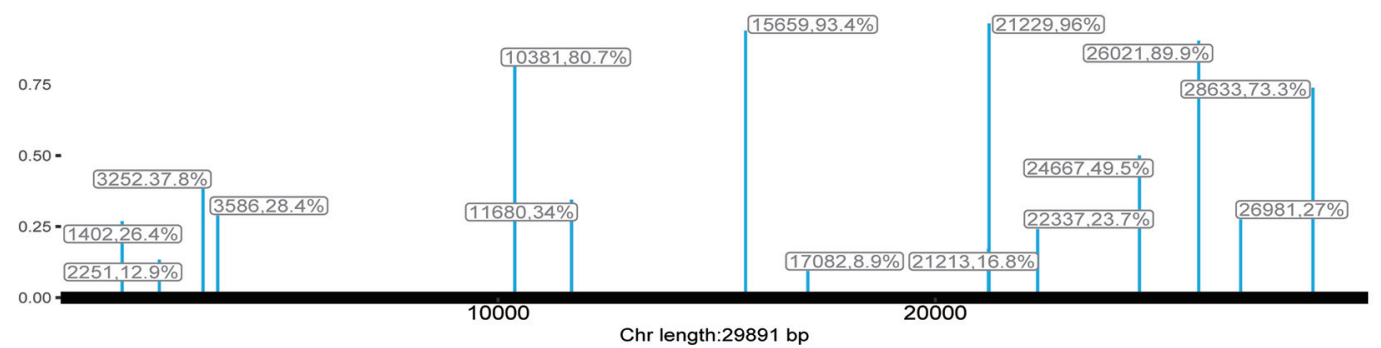

$\mathbf{F}$

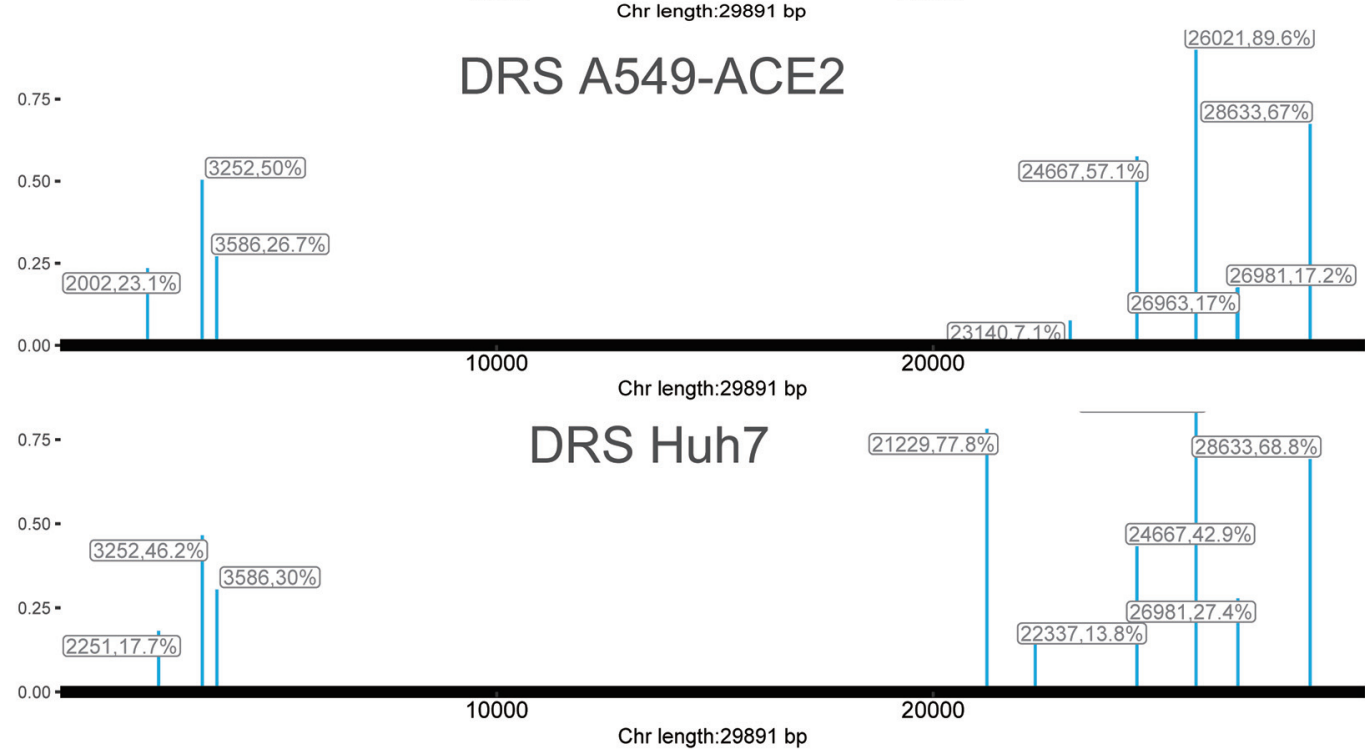

FIG 2 SARS-CoV-2 genomic RNA harbored $m^{6} \mathrm{~A}$ modifications. (A) MeRIP and Northern blotting. RNAs from virus-infected Vero E6 cells were incubated with IgG or anti- $\mathrm{m}^{6} \mathrm{~A}$-specific antibodies as indicated. Immunoprecipitated RNAs were resolved on $1 \%$ agarose gels 
the MeRIP-Seq results, most $\mathrm{m}^{6} \mathrm{~A}$ sites were distributed in the $5^{\prime}$ and $3^{\prime}$ ends (Fig. $2 \mathrm{E}$ to $\mathrm{G}$ ) in different infected cell lines. Notably, six $\mathrm{m}^{6} \mathrm{~A}$ sites were conserved in all of the infected cell lines (Fig. S1B), and the $\mathrm{m}^{6} \mathrm{~A}$ motif in the SARS-CoV-2 genome is mainly GGACA (Fig. S1E). Nine $\mathrm{m}^{6} \mathrm{~A}$ sites mapped in A549-ACE2 cells were completely included in Vero E6 cells (Fig. S1C). Three $\mathrm{m}^{6} \mathrm{~A}$ sites in Huh7 cells different from those in Vero E6 and A549-ACE2 cells (Fig. S1D). These results indicated that both the conserved and different $\mathrm{m}^{6} \mathrm{~A}$ sites existed in different cell lines.

METTL3 promoted $\mathbf{m}^{6} \mathbf{A}$ modification of SARS-CoV-2 RNA and virus replication. The host methyltransferases and demethylases are involved in the $\mathrm{m}^{6} \mathrm{~A}$ modification of EV71, HCV, ZIKV, and HIV because these viruses do not encode any enzymes with $\mathrm{m}^{6} \mathrm{~A}$ methyltransferase activity $(37-41,50,53)$. To determine whether host $\mathrm{m}^{6} \mathrm{~A}$ machinery was responsible for the SARS-CoV- $2 \mathrm{~m}^{6} \mathrm{~A}$ modification, the FLAG-tagged METTL3 gene was expressed in Vero E6 cells by transfection (Fig. 3A). Quantitative reverse transcription PCR (qRT-PCR) of the $R d R p$ gene was performed following formaldehyde-crosslinked RNA immunoprecipitation (RIP) using an anti-FLAG antibody to pull down METTL3-bound RNAs. SARS-CoV-2 RNAs were pulled down by METTL3 (Fig. 3B), indicating that SARS-CoV-2 RNA could interact with METTL3. We next knocked down endogenous METTL3 in Vero E6 cells using short hairpin RNA (shRNA) (Fig. 3D). $\mathrm{m}^{6} \mathrm{~A}$ abundance in SARS-CoV-2 RNA was detected by using qRT-PCR (Fig. 3E) or Northern blotting (Fig. 3F) after MeRIP. We found that silencing METTL3 by shRNA resulted in decreased abundance of $\mathrm{m}^{6} \mathrm{~A}$ in SARS-CoV-2 RNA (Fig. 3D and E). In contrast, overexpression of METTL3 by transfection increased the abundance of $\mathrm{m}^{6} \mathrm{~A}-$ bound SAR-CoV-2 RNAs (Fig. 3C). To further confirm our results, MeRIP-Seq was performed after METTL3 knockdown (Fig. 3G and Fig. S6). Our results showed that the methylation peaks were not changed, but that the frequency of methylation was significantly decreased, suggesting that the $\mathrm{m}^{6} \mathrm{~A}$ modification levels in the SARS-CoV-2 genome were linked to METTL3 expression. Taken together, these results indicated that METTL3 acted as a methyltransferase in the viral genome.

Viral protein expression and progeny virus production by HIV, HCV, and EV71 are affected by the expression of endogenous methyltransferases or demethylases $(37,40$, 50). Endogenous METTL3 (Fig. 4A) or FTO (Fig. 4B) in Vero E6 cells was knocked down by specific shRNAs, followed by SARS-CoV-2 infection to check whether METTL3 or FTO affected viral replication. Viral titer was measured by plaque assay, and RNA copy numbers were quantified by qRT-PCR of the $N$ or RdRp gene using standard protocols. We found that efficient knockdown of METTL3 not only resulted in significant decreases in virus titer (Fig. 4E) and viral $N$ and $R d R p$ gene copy numbers (Fig. $4 C$ and D) but also decreased expression of $\mathrm{N}$ (Fig. 4A). However, knockdown of FTO had the opposite effect (Fig. $4 B$ and $F$ to $H$ ). These results suggested that the $m^{6} A$ methyltransferase METTL3 was linked to efficient SARS-CoV-2 replication.

SRAS-CoV-2 RNA-dependent RNA polymerase (RdRp) interacted with METTL3 and facilitated its expression. In our previous study, METTL3 modulated EV71 replication by interacting with EV71 polymerase 3D and regulating 3D sumoylation and ubiquitination (50). To investigate whether there was a similar mechanism in SARS-CoV-2, pFlag-METTL3 and pHA-RdRp were cotransfected into Huh7 and HEK293T cells. The IP experiment with anti-Flag antibodies, followed by staining with anti-HA or vice versa, showed that METTL3 interacted with SARS-CoV-2 RdRp protein in the absence or presence of RNase A (Fig. $5 A$ and B, Fig. S2A and B). In addition, our study showed that RdRp interacted with the methyltransferase complex (Fig. S4A to D). To determine the functional domain interacting with METTL3, the $\mathrm{N}$ and $\mathrm{C}$ termini of RdRp were cloned

FIG 2 Legend (Continued)

containing 2.2 M formaldehyde and transferred to Hybond- $\mathrm{N}^{+}$membranes, followed by RNA signal detection with SARS-CoV-2-specific probes spanning from nt 28274 to nt 29870. (B to D) MeRIP-Seq. Fragmented total RNAs from SARS-CoV-2-infected Vero E6 cells were subjected to IP with anti-m ${ }^{6} \mathrm{~A}$-specific antibodies, followed by next-generation sequencing. Methylation coverage of the full-length SARS-CoV-2 RNA is shown. Representative of $n=2$ determinations. (E to G) DRS (direct RNA sequencing). PolyA-purified mRNAs from SARS-CoV-2-infected Vero E6, A549-ACE2, and Huh7 cells were used to nanopore-direct RNA sequencing and bioinformatic analysis. 
A
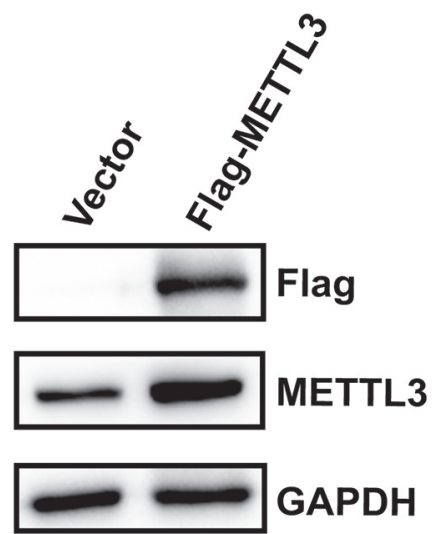

Lane 12

D

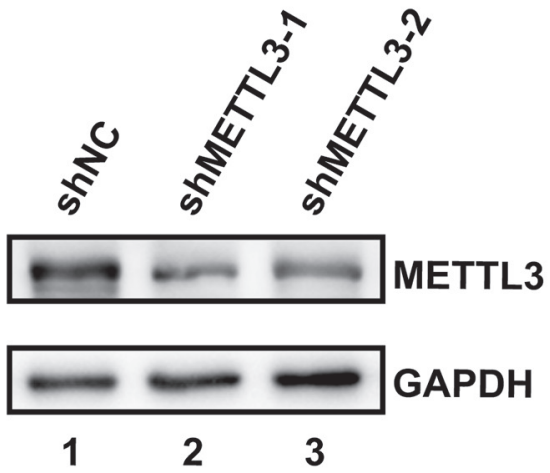

Lane $\quad 1 \quad 2 \quad 3$
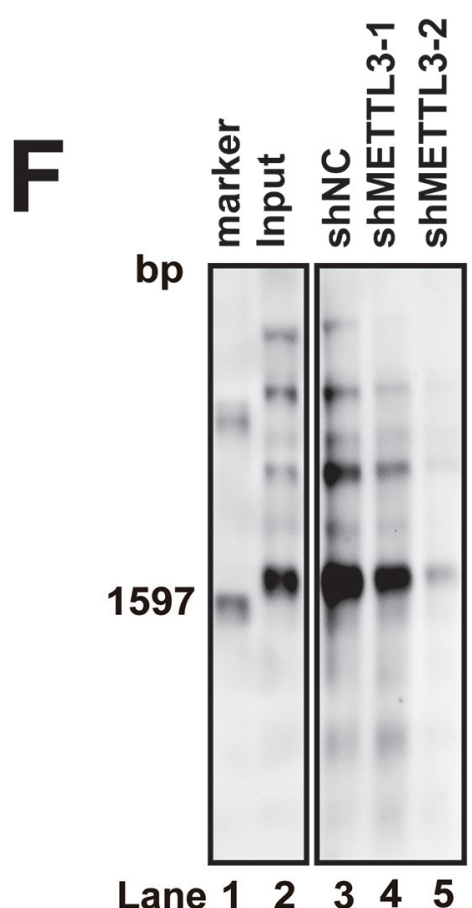

FIG 3 METTL3 catalyzed the $\mathrm{m}^{6} \mathrm{~A}$ modification of SARS-CoV-2. (A and D) Western blotting. METTL3 was knocked down by shRNA (D) or overexpressed (A) in Vero E6 cells. The expression of METTL3 was checked using anti-METTL3 (A and D) or anti-Flag antibodies (A) as (Continued on next page) 
and cotransfected with pFlag-METTL3 into Huh7 cells (Fig. 6A). We found that METTL3 interacted with RdRp-N (Fig. 6B and C) but not RdRp-C (Fig. 6D and E). To further confirm our results, the colocalization of METTL3 and RdRp was checked after cotransfection of the cells with the two plasmids. Notably, METTL3 was distributed in both the nucleus and cytoplasm when RdRp was coexpressed (Fig. 5E and F). However, the coexpression of nonstructural protein NSP16 of SARS-CoV-2 had no effect on the subcellular localization of METTL3. The colocalization of METTL3 and RdRp supported the interaction between these two proteins, which bound to viral RNAs. Moreover, METTL3 expression was increased as more RdRp was expressed by transfection or vice versa (Fig. 5C and D), suggesting that the abundance of METTL3 and RdRp influenced the expression of RdRp or METTL3.

SRAS-CoV-2 RdRp inhibited METTL3 sumoylation and ubiquitination. To analyze how viral protein RdRp affected the $\mathrm{m}^{6} \mathrm{~A}$ machinery components, we first checked the RNA abundance of all the $\mathrm{m}^{6} \mathrm{~A}$ writers, erasers, and readers after different infection times as indicated (Fig. 7A and Fig. S5). The RNA abundances of METTL3, METT14, WTAP, ALKBH5, FTO, and YTH were not changed (Fig. 7A), indicating that SARS-CoV-2 did not influence the RNA levels of $\mathrm{m}^{6} \mathrm{~A}$-related proteins. Posttranscriptional modifications, such as ubiquitination and sumoylation, affect METTL3 protein abundance and function. EV71 3D protein interacted with METTL3 and affected the expression and localization METTL3, similar to the results observed for SARS-CoV-2 infection. We next investigated whether RdRp affected the modification of METTL3. To this end, METTL3, pFlag-RdRp, HA-SUMO-1, and myc-Ubc-9 were transfected into HEK293T cells. The Western blotting results showed that sumoylation of METTL3 was reduced in the presence of RdRp expression (Fig. 7B and Fig. S3A). Cotransfection with pMETTL3, FlagRdRp, and HA-Ub resulted in decreased ubiquitination of METTL3 (Fig. 7C and Fig. S3B). Further experiments showed that overexpression of $\mathrm{RdRp}$ resulted in decreased K48-linked ubiquitination (Fig. 7D and Fig. S3C) and K63-linked ubiquitination (Fig. 7E and Fig. S3D). However, the viral nonstructural protein NSP16 overexpression had no effect on posttranslational modifications of the METTL3 (Fig. S3A to D).

\section{DISCUSSION}

In the current study, we demonstrated that SARS-CoV-2 RNA underwent $\mathrm{m}^{6} \mathrm{~A}$ modification by host $\mathrm{m}^{6} \mathrm{~A}$ machinery. The expression and localization of host $\mathrm{m}^{6} \mathrm{~A}$ components were altered during SARS-CoV-2 infection. Knockdown of METTL3 decreased the replication of SARS-CoV-2, indicating that $\mathrm{m}^{6} \mathrm{~A}$ modification played key roles in viral replication. Further studies showed that the viral polymerase RdRp interacted with METTL3 and regulated its sumoylation and ubiquitination to affect its expression and localization. Overall, our study showed that SARS-CoV-2 RNA was $\mathrm{m}^{6} \mathrm{~A}$ modified and that METTL3 played a role in regulating viral replication.

RNA modification, such as $\mathrm{m}^{6} \mathrm{~A}, \mathrm{~m}^{5} \mathrm{C}$, and ac4C, regulates viral protein expression and progeny virus production (5-10). $\mathrm{m}^{6} \mathrm{~A}$ modification has been identified in RNA viruses replicating in both the nucleus and the cytoplasm $(5,9,54)$ and has different regulation mechanisms. Similar to the RNA viruses influenza $A$ virus (IAV), human immunodeficiency virus (HIV), and enterovirus 71 (EV71) $(40,42,50,51)$, the $\mathrm{m}^{6} \mathrm{~A}$ modification of SARS-CoV-2 promotes virus replication in Vero E6 cells, which is different from the result of SARS-CoV-2 infection in Huh7 cells (47). The $\mathrm{m}^{6} \mathrm{~A}$ modification of viral RNAs attenuates host innate immunity via RIG-I signaling in virus infection, indicating

FIG 3 Legend (Continued)

indicated. Vector-transfected cells were used as a control. (B) Formaldehyde-RIP qRT-PCR. Cell lysates from formaldehyde-cross-linking were subjected to IP with IgG or anti-Flag antibodies. qRT-PCR was performed to quantify SARS-CoV-2 RNA. IgG was used as a negative control. Unpaired Student's $t$ tests were performed, and the data are presented as means \pm standard errors of the means $(n=3) .{ }^{* *}, P \leq 0.01$. (C and E) MeRIP-qPCR. RNA was extracted from SARS-CoV-2-infected Vero E6 cells in which METTL3 was overexpressed (C) or knocked down by shRNA (E). MeRIP was performed, and SARS-CoV-2 RNA was quantified by qRT-PCR. Unpaired Student's $t$ tests were performed, and data are presented as means \pm standard errors of the means $(n=3)$. ${ }^{*}, P \leq 0.01$. (F) MeRIP and Northern blotting. RNAs were harvested from SARSCoV-2-infected Vero E6 cells in which METTL3 was knocked down by shRNA. (G) MeRIP-Seq. Total RNA was isolated from SARS-CoV-2infected Vero E6 cells in which METTL3 was knocked down. 
A
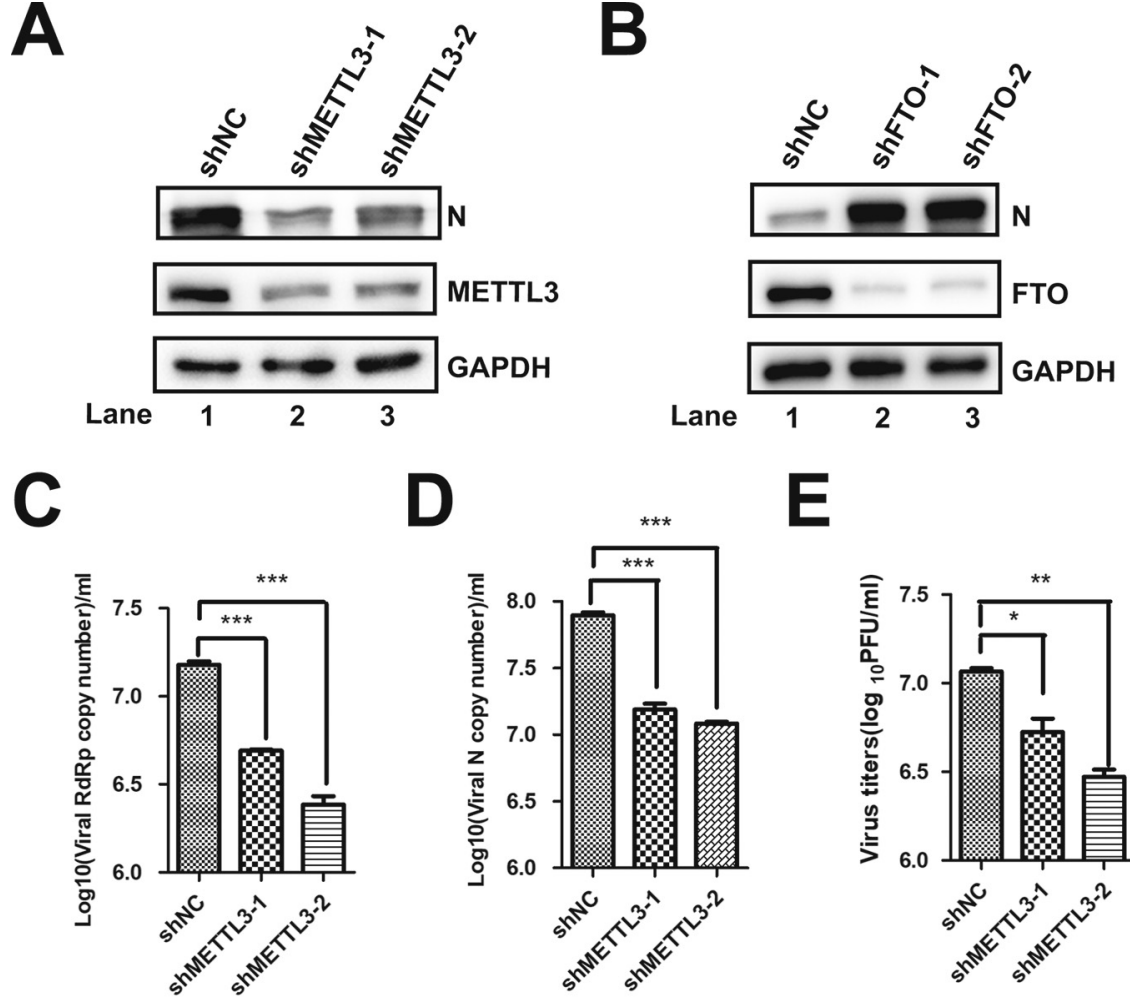

D

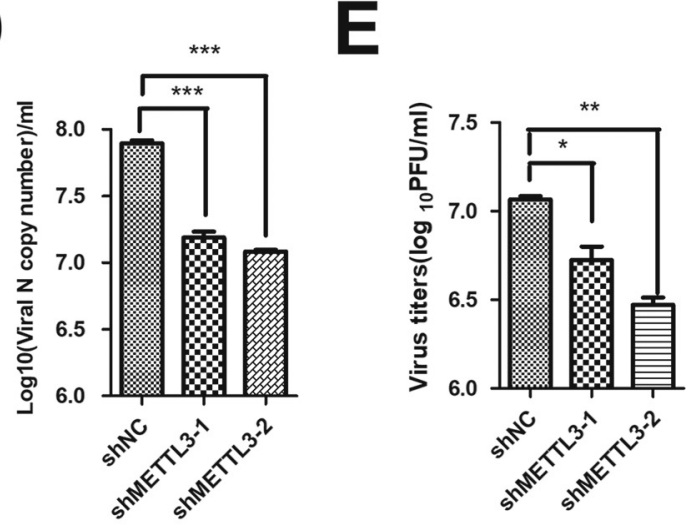

$\mathbf{F}$

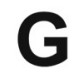

H
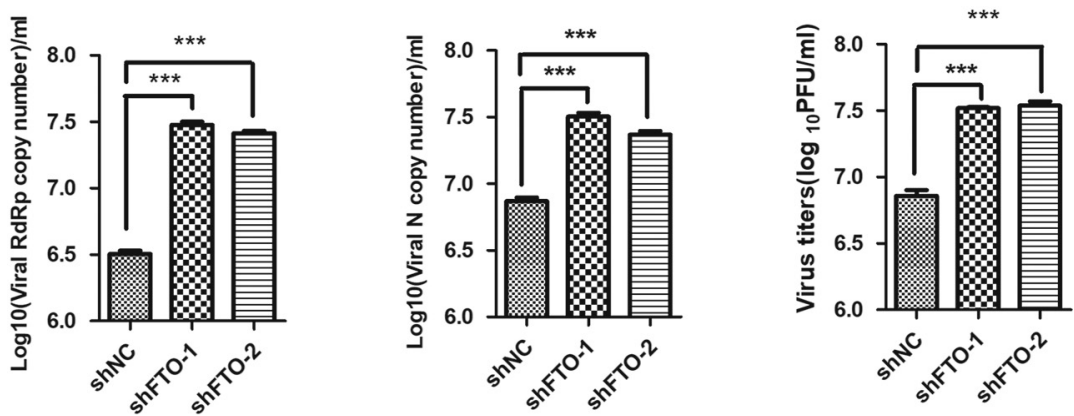

FIG 4 METTL3- and FTO-regulated SARS-CoV-2 replication. (A and B) Western blotting. METTL3 and FTO were knocked down in Vero E6 cells by shRNA. The expression of METTL3, FTO, and viral N protein were detected by Western blotting with specific antibodies. ( $C$ and D, F, and G) qRT-PCR. Total RNA was isolated from SARS-CoV-2-infected Vero E6 cells in which METTL3 and FTO was knocked down by shRNA as indicated. SARS-CoV-2 RNA was quantified using qRT-PCR with specific primers targeting $N$ and RdRp genes. GAPDH was used as a control. Unpaired Student's $t$ tests were performed. Data are presented as means $\pm \operatorname{SEMs}(n=3)$. ${ }^{*}, P \leq 0.05$. (E and H) Viral titers. Vero E6 cells in which METTL3 and FTO were knocked down were infected by SARS-CoV-2, and the supernatants were collected at $24 \mathrm{~h}$ postinfection to measure virus titers by plaque assay.

that the interferon pathway is linked to the viral $\mathrm{m}^{6} \mathrm{~A}$ modification (55-57). As Vero E6 cells are immunodeficient, the regulatory mechanism in our research may be different from the reported literature.

The location and pattern of $\mathrm{m}^{6} \mathrm{~A}$ between virus and host RNA are different. In our study, we assessed the internal $\mathrm{m}^{6} \mathrm{~A}$ modification status of SARS-CoV-2 RNA by MeRIPSeq and DRS. The results demonstrated that $\mathrm{m}^{6} \mathrm{~A}$ peaks were mainly distributed in both $5^{\prime}$ and $3^{\prime}$ ends spanning the ORF1ab-, N-, and ORF10-encoding regions in different cell lines. The $\mathrm{m}^{6} \mathrm{~A}$ modification pattern of SARS-CoV-2 is very similar to that of host mRNAs $(12,58)$ but different from that of EV71, whose $m^{6} A$ sites are distributed in 


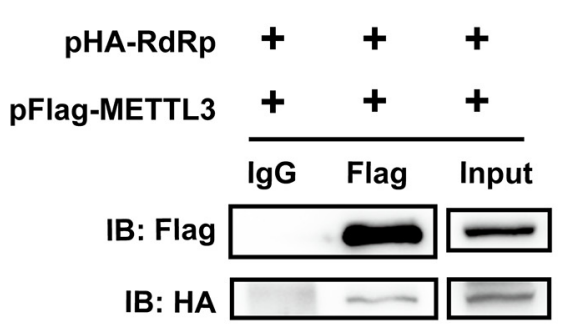

\section{B}

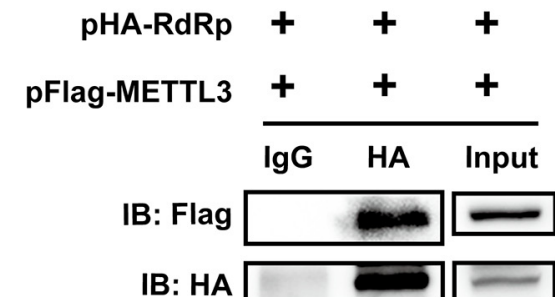

IB: HA
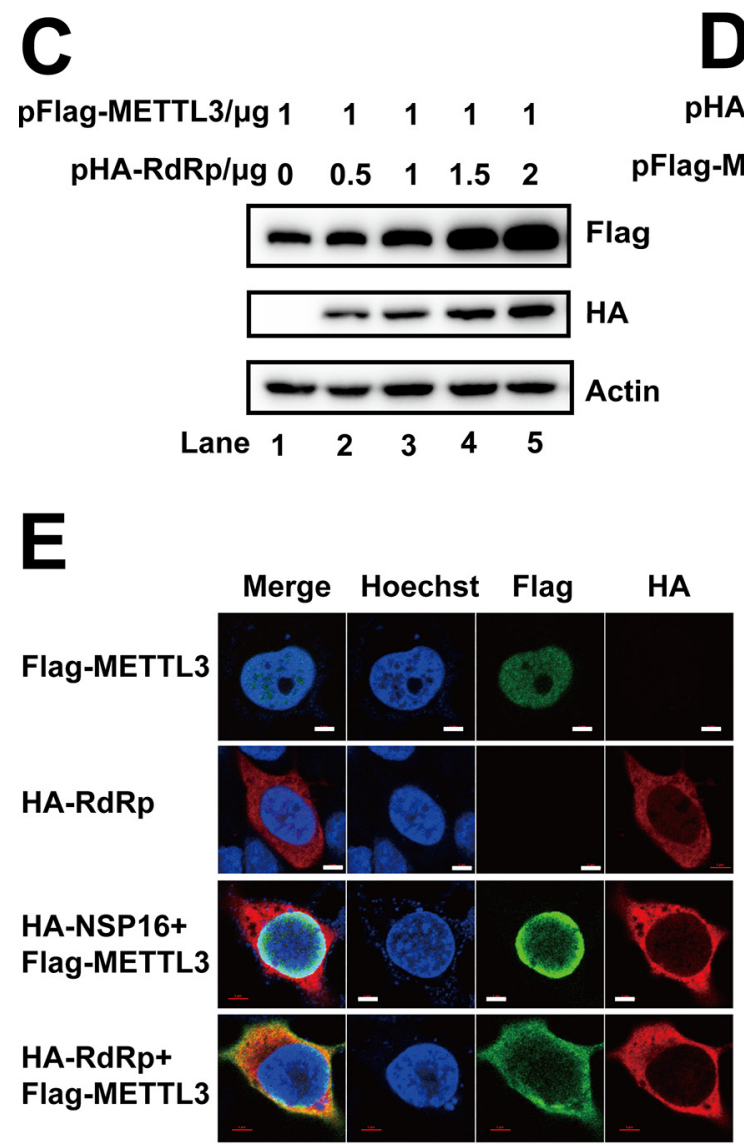
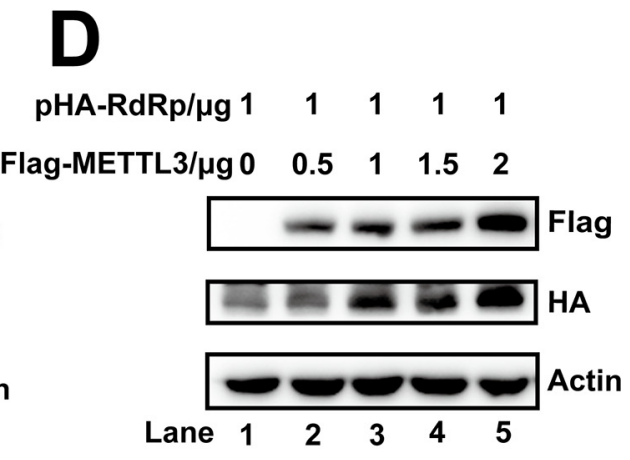

$\mathbf{F}$

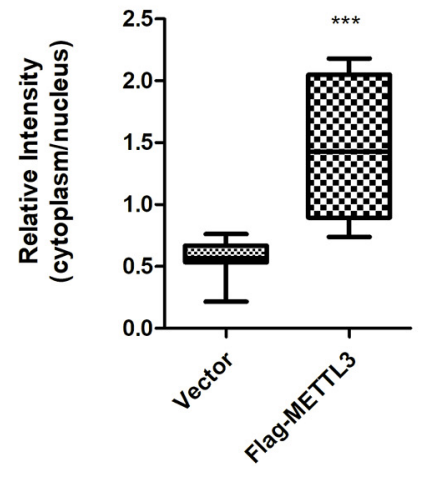

FIG 5 SRAS-CoV-2 RdRp interacted with METTL3 and influenced its expression. (A and B) Western blotting. pFlag-METTL3 and pHA-RdRp were cotransfected into Huh7 cells, and co-IP was performed with anti-HA (A) or anti-Flag (B) antibodies. IgG antibodies were used as a control. The IP samples were pulled down with anti-Flag (A) or anti-METTL3 (B) antibodies. (C and D) Western blotting. Huh7 cells were transfected with $1 \mu \mathrm{g}$ pFlagMETTL3 (C) or pHA-RdRp (D) together with different amounts of pHA-RdRp (C) or pFlag-METTL3 (D) $(0,0.5,1$, 1.5 , and $2 \mu \mathrm{g}$, respectively) in six-well plates. The expression of METTL3 and RdRp was detected by Western blotting. (E) Confocal microscopy images. Huh7 cells were transfected with pFlag-METTL3 with or without HARdRp and HA-NSP16 transfection. Costaining was performed using anti-Flag (green) and anti-HA antibodies (red). The nucleus (blue) was stained with Hoechst. (F) Relative fluorescence intensity of METTL3 in the cytoplasm versus the nucleus was quantified using ImageJ and graphed in box-and-whisker plots, representing the minimum, first quartile, median, third quartile, and maximum. Unpaired Student's $t$ test was performed $(n \geq 10) .{ }^{* * *}, P \leq 0.001$.

coding regions of the middle of the viral genome (50). Notably, $44 \mathrm{~m}^{6} \mathrm{~A}$ motifs were found in the 5 enriched peaks, most of which were distributed in the $\mathrm{N}$ gene region.

SARS-CoV-2 infection resulted in not only elevated expression of METTL3 but also altered distribution in both the nucleus and cytoplasm. We also found that METTL14, WTAP, ALKBH5, and FTO colocalized with the viral protein N, supporting the finding that SARS-CoV-2 infection affected the $\mathrm{m}^{6} \mathrm{~A}$ methyltransferase and demethylases. The 
A

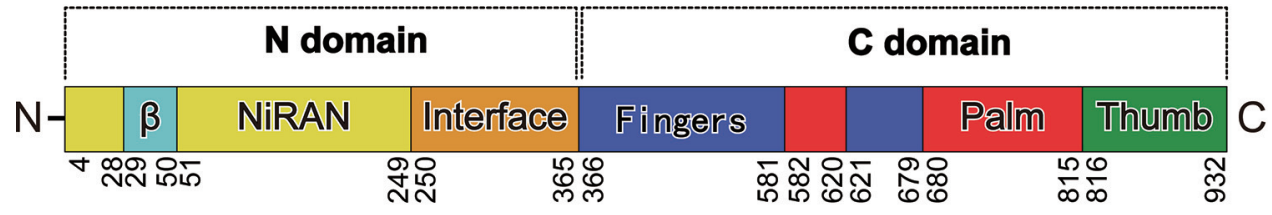

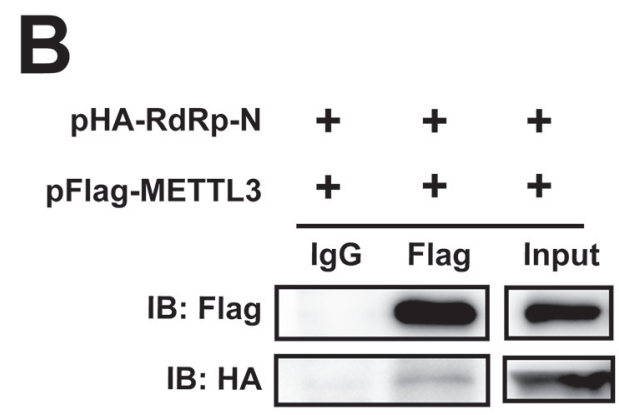

\section{C}
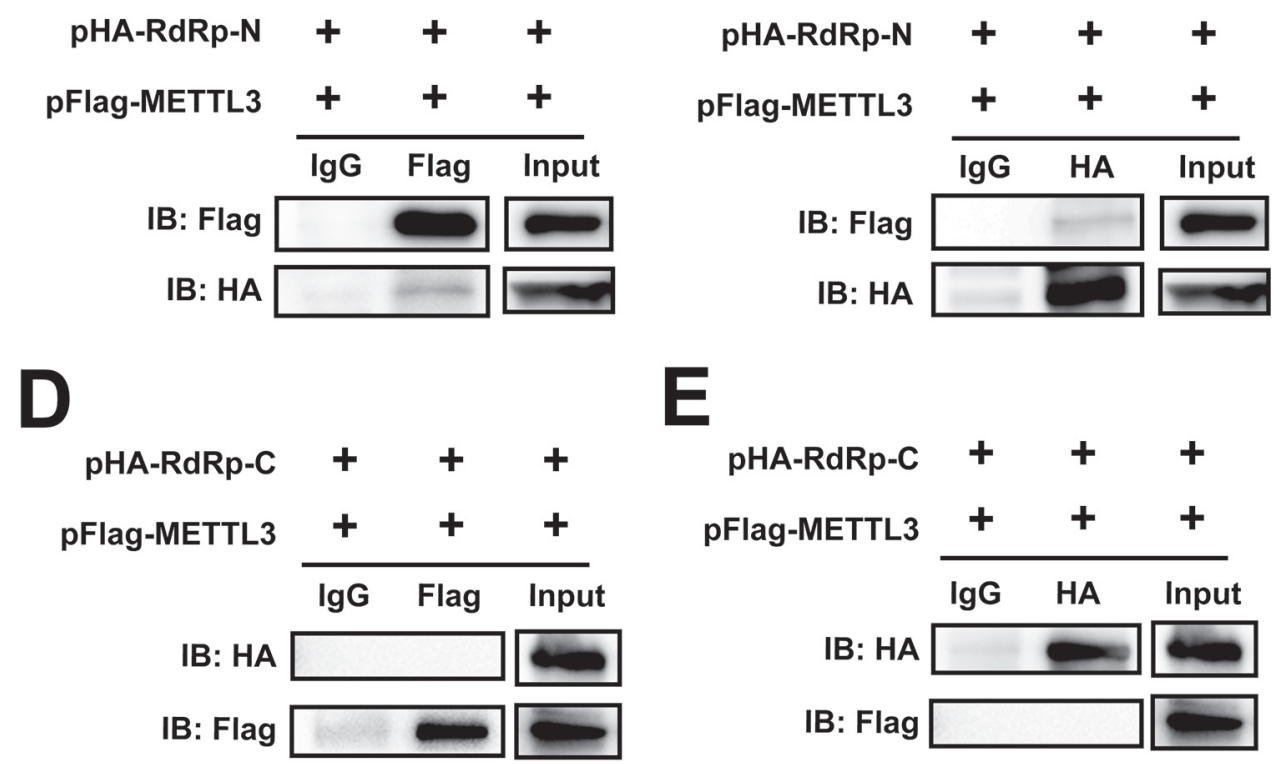

FIG 6 The $\mathrm{N}$ terminus of RdRp interacted with the METTL3. (A) Schematic diagram of the RdRp domain. The $\mathrm{N}$-terminal and C-terminal domains consist of 1-365AA and 366-932AA, respectively. (B to E) Western blotting. Huh7 cells were cotransfected with pFlag-METTL3 and pHA-RdRp-N (B and C) or pHA-RdRp-C (D and E). Co-IP was performed with anti-HA (C and E) or anti-Flag (B and D) antibodies. IgG antibody was used as a control. The immunoblots were visualized by the indicated antibodies.

colocalization of viral $\mathrm{N}$ and host $\mathrm{m}^{6} \mathrm{~A}$ proteins supported the finding that the $\mathrm{m}^{6} \mathrm{~A}$ modification machinery could modify cytoplasmic SARS-CoV-2 RNA during infection. In our previous study, we found that METTL3 interacted with EV71 polymerase 3D protein (50). Cotransfection of cells with METTL3 and 3D resulted in both nuclear and cytoplasmic distribution of METTL3, implying that 3D played roles in the distribution of METTL3 in the cytoplasm; however, the specific mechanism is still unknown. In the current study, we found that the SARS-CoV-2 RdRp protein induced the expression and cytoplasmic distribution of METTL3.

Most RNA viruses that replicate in the cytoplasm, including ZIKV, West Nile virus, PEDV, and EV71, hijack the host $\mathrm{m}^{6} \mathrm{~A}$ machinery to modify the RNA and therefore do not encode methyltransferase $(37,38,50,52)$. SARS-CoV-2 nonstructural proteins NSP14 and NSP16 have methyltransferase function and play key roles in the $\mathrm{m}^{7} \mathrm{G}$ cap and 2'-O-methylation modification (59-61). Our study showed that METTL3 interacted with SARS-CoV-2 RNA. Notably, the expression of METTL3 is linked to the $\mathrm{m}^{6} \mathrm{~A}$ modification level of SARS-CoV-2 RNA. Knocking down METTL3 resulted in decreased $\mathrm{m}^{6} \mathrm{~A}$ modification of SARS-CoV-2 RNA, which was detected either by MeRIP Northern blotting or by MERIP-Seq. However, overexpression of METTL3 resulted in elevated $\mathrm{m}^{6} \mathrm{~A}$ modification, suggesting that METTL3 may be the methyltransferase modifying viral RNA. METTL3 is a multifunctional protein that functions during EV71 infection. Viral RdRp 3D protein binds to the methyltransferase complex, and METTL3 regulates the 
A

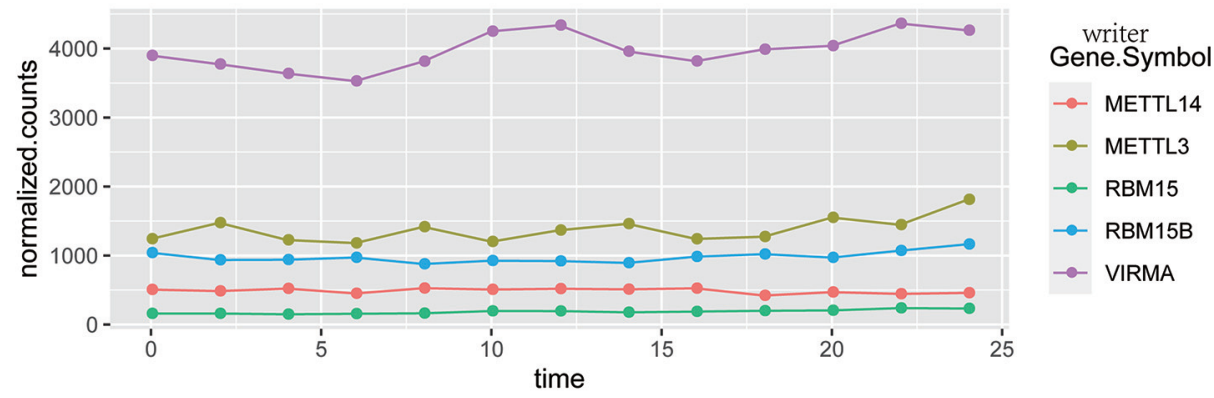

B

C

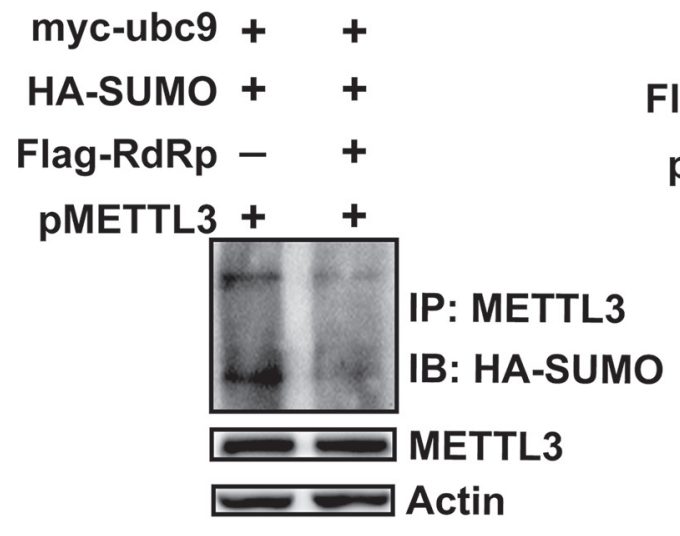

$\begin{array}{rr}\text { HA-Ubi }+ & + \\ \text { Flag-RdRp }- & + \\ \text { pMETTL3 }+ & +\end{array}$

IP: METTL3

IB: HA-Ubi

D
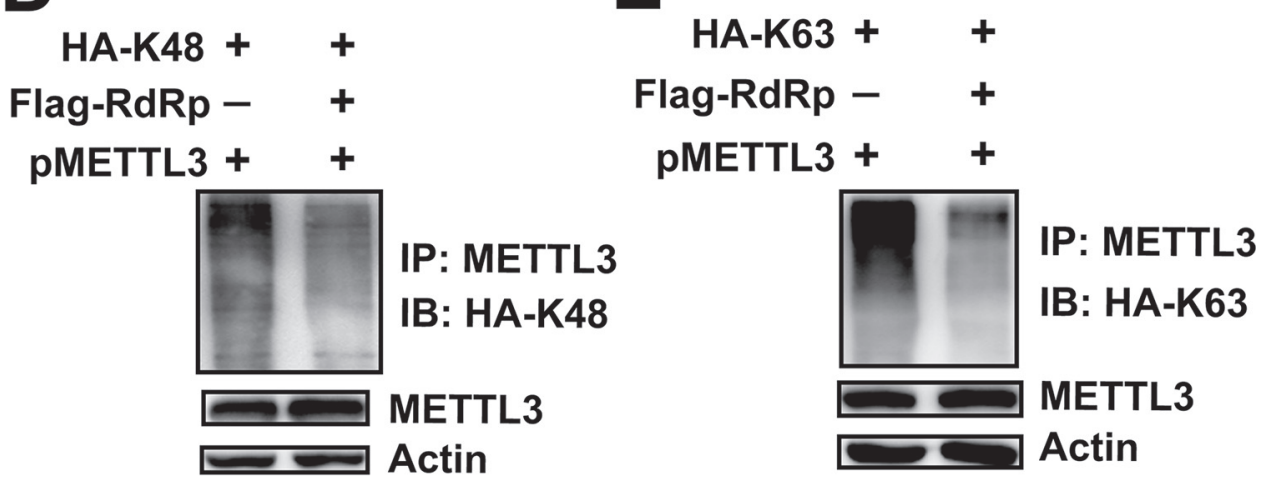

FIG 7 RdRp expression inhibited the sumoylation and ubiquitination of METTL3. (A) RNA expression of host methyltransferases. Total RNA was harvested from SARS-CoV-2-infected Vero E6 cells every $2 \mathrm{~h}$ as indicated. The mRNAs were separated and subjected to next-generation sequencing. RNA levels of host methyltransferases were normalized according to the sequencing reads. (B) Sumoylation assay. METTL3 was overexpressed in HEK293T cells by transfection with pMETTL3, followed by transfection with pFlag-RdRp, pHASUMO-1, and pMyc-Ubc9. IP and immunoblot analyses were performed using the indicated antibodies for the sumoylation assay. (C to E) Ubiquitination assay. HEK293T cells were transfected with pFlag-RdRp, pHA-Ubi, pHA-K48, and PHA-K63 after METTL3 overexpression. IP and immunoblot analyses were performed using the indicated antibodies.

ubiquitination of 3D to promote viral replication (50). In this study, knockdown of METTL3 resulted in decreased SARS-CoV-2 replication; this result could be explained by the absence of METTL3 methyltransferase activity, which catalyzes the methylation of viral RNA. To address whether key proteins of SARS-CoV- 2 interacted with $\mathrm{m}^{6} \mathrm{~A}$ components to facilitate virus replication, we checked the interactions of METTL3 with viral RdRp, which bound to viral RNA. The results showed that METTL3 not only interacted 
with RdRp but also promoted RdRp expression; the opposite result was also true. In contrast to EV71 3D protein, for which posttranslational modification was modulated by METTL3, SARS-CoV-2 RdRp expression altered the localization pattern of METTL3. The distribution of METTL3 in the presence of RdRp expression confirmed the interaction between METTL3 and RdRp and may explain the presence of METTL3 in the cytoplasm during SARS-CoV-2 infection. Sumoylation and ubiquitination affect the function and expression of METTL3, respectively (62). To elucidate how RdRp expression increased the expression of METTL3, we checked the protein modification of METTL3. The results showed that RdRp expression decreased the sumoylation and overall ubiquitination levels. Moreover, K48- and K63-linked ubiquitination levels were reduced. These data supported that RdRp not only promoted methyltransferase activity but also increased METTL3 expression by decreasing its ubiquitination.

In summary, our results provided evidence that the host $\mathrm{m}^{6} \mathrm{~A}$ machinery interacted with viral key proteins to facilitate the replication of SARS-CoV-2. First, METTL3 functioned as a methyltransferase, adding the $\mathrm{m}^{6} \mathrm{~A}$ modification to viral RNA. Second, METTL3 interacted with viral RdRp, which resulted in METTL3 distribution both in the nucleus and in the cytoplasm. Importantly, RdRp boosted the expression of METTL3 by altering the ubiquitination pattern through an unknown mechanism. Further studies are required to elucidate this mechanism. The functional $m^{6} \mathrm{~A}$ sites on the SARS-CoV- 2 RNA need to be defined on the infectious clone to further verify the influence of $m^{6} A$ modification on virus replication.

Data availability. SARS-CoV-2 sequence data that support the findings of this study have been deposited in GISAID (https://www.gisaid.org/) with the accession numbers EPI_ISL_402124, EPI_ISL_402127 to EPI_ISL_402130, and EPI_ISL_402131; in GenBank with accession numbers MN996527 to MN996532; and in the National Genomics Data Center, Beijing Institute of Genomics, Chinese Academy of Sciences (https://bigd.big.ac .cn/databases?lang=en) with accession numbers SAMC133236 to SAMC133240 and SAMC133252.

\section{MATERIALS AND METHODS}

Virus, cell lines, and cell culture. SARS-CoV-2 (IVCAS 6.7512) was obtained from the Virus Resource Center of the Wuhan Institute of Virology of the Chinese Academy of Sciences and passaged in monkey kidney cells (Vero E6 cells) for eight generations. The titer of the SARS-CoV-2 working solution was $10^{6}$ $\mathrm{PFU} / \mathrm{ml}$, as determined by plaque assays in Vero E6 cells. Vero E6 cells (American Tissue Culture Collection [ATCC], Manassas, VA, USA; CRL-1586), and HEK293T cells (ATCC; CRL-11268), A549-ACE2 (ATCC, CCL-185), and Huh7 liver hepatocellular cancer cells (obtained from the Wuhan Institute of Virology of the Chinese Academy of Sciences) were cultured in Dulbecco's modified Eagle's medium 116 (Gibco, Gaithersburg, MD, USA) containing $10 \%$ fetal bovine serum (Gibco) at $37^{\circ} \mathrm{C}$ with $5 \% \mathrm{CO} 2$.

Plasmid construction and transfection. The RNA-dependent RNA polymerase (RdRp) plasmids and nonstructural protein 16 (NSP16) pFlag-RdRp, pHA-RdRp, pFlag-NSP16, and pHA-NSP16 were constructed by inserting the sequences of the RdRp and NSP16 open reading frame (ORF) into the vectors pXJ40-Flag and pXJ40-HA (Sigma-Aldrich, St. Louis, MO, USA), respectively. The N- and C-terminal domains of RdRp were also cloned into the vector pXJ40-HA. ${ }^{6} \mathrm{~A}$ methyltransferases and demethylase expression plasmids (pFlag-METTL3, pFlag-WTAP, pMETTL3, pMETTL14, and Flag-METTL3) were constructed by inserting the ORF sequences of the genes into the vector pXJ40-Flag, pcDNA3.0, or pLentiCMV-3XFlag. The plasmids HA-SUMO-1, HA-Ubi, HA-63, HA-48, and myc-Ubc9 were kind gifts from Hanzhong Wang (Wuhan Institute of Virology, Chinese Academy of Sciences [CAS]).

Plasmids were transfected into cells using Lipofectamine 2000 reagent (Invitrogen, Carlsbad, CA, USA; catalog [cat.] no. 11668-019) according to the manufacturer's instructions.

Western blotting and antibodies. Cell lysates were prepared at the indicated times after transfection or infection and separated by gradient sodium dodecyl sulfate polyacrylamide gel electrophoresis (SDS-PAGE) on $10 \%$ gels, and proteins were then transferred to nitrocellulose membranes. The membranes were incubated with primary antibodies overnight at $4^{\circ} \mathrm{C}$ at the dilution suggested by the manufacturer's protocols. The primary antibodies were as follows: anti-glyceraldehyde 3-phosphate dehydrogenase (GAPDH; cat. no. 60004-1-lg; Proteintech, Rosemont, IL, USA), mouse monoclonal anti- $\beta$-actin (cat. no. sc47778; Santa Cruz Biotechnology, Dallas, TX, USA), rabbit monoclonal anti-METTL3 (cat. no. 15073-1-AP; Proteintech), anti-METTL3 (cat. no. ab195352; Abcam, Cambridge, UK), anti-METTL14 (cat. no. SAB1104405; Sigma-Aldrich), anti-WTAP (cat. no. ab155655; Abcam), anti-ALKBH5 (cat. no. ab69325; Abcam), anti-FTO (cat. no. ab124892; Abcam), anti-Flag (cat. no. F1804-1 MG; Sigma-Aldrich), anti-HA (cat. no. H9658; Sigma-Aldrich), and mouse polyclonal anti-SARS-CoV-2 nonstructural protein (NP) (gift from Fei Deng, Wuhan Institute of Virology, CAS). The secondary antibodies, including goat anti-mouse IgG and goat anti-rabbit IgG (AntiGene Biotech GmbH, Stuttgart, Germany) were incubated for $1 \mathrm{~h}$ at a 
dilution of 1:5,000. Luminescent signals were detected using a Tanon-5200 ChemiDoc MP imaging system (Tanon Science \& Technology, Shanghai, China).

Coimmunoprecipitation. Total proteins were collected $48 \mathrm{~h}$ after transfection. Primary antibodies were mixed with supernatants of cell lysates ( $2 \mu \mathrm{g}$ primary antibody per $1 \mathrm{mg}$ protein sample) for $2 \mathrm{~h}$ at $4^{\circ} \mathrm{C}$ and then incubated with protein $\mathrm{G}$ agarose overnight at $4^{\circ} \mathrm{C}$. Immunoprecipitated proteins were separated by SDS-PAGE on $12 \%$ gels and transferred nitrocellulose membranes, followed by incubation with primary and second antibodies. Protein detection was performed using a Tanon 5200 ChemiDoc MP imaging system.

Short hairpin RNA (shRNA) knockdown. First, shRNA knockdown was performed according to the protocol for shRNA-mediated gene silencing and lentiviral particle packaging from the Addgene website. Stable-knockdown Vero E6 cell lines were screened using $10 \mu \mathrm{g} / \mathrm{ml}$ puromycin for selection. shRNAspecific primers were as follows: METTL3 (shMETTL3-1: 5'-GCCAAGGAACAATCCATTGTT-3', shMETTL3-2: 5'-CGTCAGTATATTGGGCAAGTT-3'), FTO (shFTO-1: 5'-TCACCAAGGAGACTGCTATTT-3', shFTO-2: 5'GATCCAAGGCAAAGATTTACT-3').

Immunofluorescence analysis. Immunofluorescence analyses were performed as previously described (63). Briefly, Vero E6 cells were infected with SARS-CoV-2 (multiplicity of infection $[\mathrm{MOI}]=0.01$ ) and harvested $24 \mathrm{~h}$ postinfection. Cells were fixed in 4\% paraformaldehyde overnight, permeabilized in $0.2 \%$ Triton X-100 for $10 \mathrm{~min}$, washed three times with phosphate-buffered saline (PBS), and blocked in $3 \%$ bovine serum albumin for $1 \mathrm{~h}$ at room temperature. The cells were incubated with primary antibodies overnight at $4^{\circ} \mathrm{C}$ at the dilution suggested by the manufacturer's protocol and stained with secondary antibodies (Alexa Fluor 488, Alexa Fluor 568) for $1 \mathrm{~h}$ after three washes with PBS. Nuclei were visualized with Hoechst 33258 at a dilution of 1:1,000. The images were captured under a PerkinElmer VoX confocal microscope.

Quantitative reverse transcription PCR (qRT-PCR). Total RNA was extracted from SARS-CoV-2infected Vero E6 cells, and reverse transcription was performed using a HiScript first-strand cDNA synthesis kit (Vazyme Biotech Co., Nanjing, China) according to the manufacturer's instructions, followed by quantitative PCR with SYBR green (Yeasen Biotech Co., Shanghai, China) on a CFX Connect real-time system (Bio-Rad Laboratories, Hercules, CA, USA). GAPDH, $N$, and RdRp gene-specific primers are described in Table S1.

Plaque assay. SARS-CoV-2 was propagated on the Vero E6 cells and titrated by single-layer plaque assay with a standard procedure. Briefly, Vero E6 cells were seeded into 24-well plates at a concentration of $1 \times 10^{5}$ cells per well. Then, $24 \mathrm{~h}$ later, confluent Vero E6 cells were infected with $200 \mu$ l of DMEM containing a serial 10 -fold dilution of viral stock for $1 \mathrm{~h}$ at $37^{\circ} \mathrm{C}$. After removal of the inoculum, Vero E6 cells were overlaid with DMEM medium containing $0.9 \%$ methylcellulose and cultured at $37^{\circ} \mathrm{C}$ for 4 days. Plaques were monitored and counted.

Formaldehyde-cross-linked RNA-immunoprecipitation (RIP). RIP was conducted as previously described (50). Briefly, infected Vero E6 cells were cross-linked by adding PBS containing 1\% methanolfree formaldehyde and incubated for $10 \mathrm{~min}$ at $37^{\circ} \mathrm{C}$. The reaction was terminated by adding $2.5 \mathrm{M}$ glycine, and the cells were lysed with $400 \mu \mathrm{l}$ RIP buffer $(150 \mathrm{mM} \mathrm{KCl}, 25 \mathrm{mM}$ Tris- $\mathrm{HCl}$ [pH 7.4], $5 \mathrm{mM}$ ethylenediaminetetraacetic acid [EDTA], $0.5 \mathrm{mM}$ dithiothreitol [DTT], 0.5\% NP-40, $100 \mathrm{U} / \mathrm{ml}$ RNase inhibitor, $100 \mu \mathrm{M}$ phenylmethylsulfonyl fluoride [PMSF], and $1 \mu \mathrm{g} / \mathrm{ml}$ proteinase inhibitor) on ice for $10 \mathrm{~min}$. The lysates were then centrifuged at $16,000 \times g$ for $10 \mathrm{~min}$, and supernatants were subjected to IP with IgG or anti-Flag antibodies overnight. Next, $30 \mu \mathrm{l}$ protein-G agarose beads was added after washing three times with washing buffer $(300 \mathrm{mM} \mathrm{KCl}, 25 \mathrm{mM}$ Tris- $\mathrm{HCl}$ [pH 7.4], $5 \mathrm{mM}$ EDTA, $0.5 \mathrm{mM}$ DTT, 0.5\% NP-40, $100 \mathrm{U} / \mathrm{ml}$ RNase inhibitor, $100 \mu \mathrm{M}$ PMSF, and $1 \mu \mathrm{g} / \mathrm{ml}$ proteinase inhibitor) and incubated with the indicated antibodies for $2 \mathrm{~h}$ at $4^{\circ} \mathrm{C}$. RNA isolation was performed using TRIzol (Invitrogen, Carlsbad, CA, USA) for qRT-PCR

MeRIP-Seq. Total RNA was extracted from SARS-CoV-2-infected Vero E6 cells and purified with an Oligo (dT) kit (Thermo Scientific, Wilmington, DE, USA). The polyA purified RNA was fragmented and subjected to IP using an $\mathrm{m}^{6} \mathrm{~A}$-specific antibody, followed by next-generation sequencing. MeRIP-Seq data were analyzed as described previously (44). Briefly, reads were quality-checked with FastQC v0.11.8 (http://www.bioinformatics.babraham.ac.uk/projects/fastqc), and then fastp v0.20.1 (64) was used to trim and filter low-quality reads. HISAT 2 (65) was used to align reads to the SARS-CoV-2 reference genome NC_045512. IP and input-normalized coverage were reported in counts per million mapped reads (CPM) using bamCoverage from deepTools (66), with the parameters -binSize 1 -effectiveGenomeSize 29903 -normalizeUsing CPM -p max/2. To make reads depth of IP comparable among the four samples, we normalized IP reads mapping to the virus genome to the total number of sequenced reads to eliminate library differences. IP over input peaks were detected using MACS2 v2.2.7.1 (67), callpeak, using the parameters -f BAMPE -B -g 29903 -nomodel -extsize 200 -scale-to small -bdg -keep-dup=1 -q 0.001.

Nanopore direct RNA sequencing (DRS). DRS was described previously (49). First, 1 mg total RNA was extracted from SARS-CoV-2-infected Vero E6, A549-ACE2, and Huh7 cells and purified with an Oligo (dT) kit (Thermo Scientific, Wilmington, DE, USA). Then RNA samples were library prepared following the manufacturer's instructions (the Oxford Nanopore DRS protocol, SQKRNA002) and loaded on a FLO-MIN106D flow cell, followed by a 48-h sequencing run on a MinION device (Oxford Nanopore Technologies).

We used the sequence of the Wuhan-Hu-1 strain (IVCAS 6.7512) as the viral reference genome, and the nanopore direct sequencing data was analyzed by BENAGEN (Nanopore Company). A threshold with a $\mathrm{Q}$ value of 7 was set to obtain pass reads, and base-calling was performed using guppy v3.4.5 (Oxford Nanopore Technologies). The multi to single fast5 of ont fast5 api (v3.1.6; https://github.com/ nanoporetech/ont_fast5_api) was used to convert multi-fast5 reads to single reads, followed by the MINES analysis process $(68)$. First, we used tombo $(\mathrm{v} 1.5 ; 69)$ to resquiggle (default parameters) the fast5 data. The de novo noncanonical base method mode (tombo detect_modifications de_novo -coverage- 
dampen-counts 0 ) was applied to detect the bases at each position on the viral genome to check the methylation ratio and coverage of each base. The m6A site was identified using MINES (cDNA_MINES.py, default parameters). Finally, the logo of the m6A motif was drawn with visual analysis using the ggseqlogo package(vggseqlogo_0.1) (70).

MeRIP and Northern blotting. For MeRIP and Northern blotting, $400 \mu \mathrm{g}$ total RNA from virusinfected Vero E6 cells was incubated with an anti- $\mathrm{m}^{6} \mathrm{~A}$ antibody (Synaptic Systems, Gottingen, Germany) or an IgG antibody in $300 \mu \mathrm{IIP}$ buffer $\left(150 \mathrm{mM} \mathrm{NaCl}, 0.1 \% \mathrm{NP}-40,10 \mathrm{mM}\right.$ Tris- $\mathrm{HCl}$ [pH 7.4]) for $2 \mathrm{~h}$ at $4^{\circ} \mathrm{C}$. Then $35 \mu$ l magnetic beads (New England Biolabs [NEB]; goat anti-rabbit magnetic beads; cat. no. S1432S) was added, and samples were washed three times and rotated for $2 \mathrm{~h}$ at $4^{\circ} \mathrm{C}$. The beads were washed six times and incubated with $300 \mu$ l elution buffer $(5 \mathrm{mM}$ Tris- $\mathrm{HCl}$ [pH 7.5], $1 \mathrm{mM}$ EDTA [pH 8.0], 0.05\% SDS, and $8.4 \mu \mathrm{l} 10-\mathrm{mg} / \mathrm{ml}$ proteinase $\mathrm{K}$ ) for $1.5 \mathrm{~h}$ at $50^{\circ} \mathrm{C}$. The RNA was purified using phenol-chloroform and precipitated with ethanol. For qRT-PCR, CDNA was synthesized using a reverse transcriptase mix (Vazyme), and relative quantification was performed using specific primers. The data were normalized to the quantification cycle $\left(C_{q}\right)$ values of GAPDH. For Northern blotting, the purified RNA was run on a $1.0 \%$ agarose gel containing $2.2 \mathrm{M}$ formaldehyde for $11 \mathrm{~h}$ at $35 \mathrm{~V}$, followed by transfer to a Hybond-N+ membrane and UV cross-linking. Finally, membranes were hybridized with a DIG-labeled SARS-CoV-2 probe (nt 28274 to 29870), and probe detection was performed using a luminescence detection kit II (Roche) according to the manufacturer's protocol. Signals were detected using a ChemiDoc MP imaging system (Tanon 5200).

Sumoylation and ubiquitination assays. Sumoylation and ubiquitination assays were performed as previously described (71). Briefly, the indicated plasmids were cotransfected into HEK293T cells, and the cell lysates were harvested by centrifugation at $16,000 \times g$ at $4^{\circ} \mathrm{C}$ for $10 \mathrm{~min}$. Next, $50 \mu \mathrm{l}$ protein $\mathrm{G}$ Dynabeads was incubated with $10 \mu \mathrm{g}$ of the indicated antibodies for $2 \mathrm{~h}$, followed by incubation with cell lysates overnight. The complexes were washed six times with PBS containing $0.02 \%$ Tween 20 and subjected to Western blotting.

Statistical analysis. The statistical analysis of the qRT-PCR data was performed using two-tail unpaired $t$ tests in Prism Software (GraphPad Software, La Jolla, CA, USA.). Data are presented as means \pm standard deviations $(n=3)$. All experiments were repeated at least three times.

\section{SUPPLEMENTAL MATERIAL}

Supplemental material is available online only.

FIG S1, TIF file, 1.7 MB.

FIG S2, TIF file, 0.5 MB.

FIG S3, TIF file, 1.8 MB.

FIG S4, TIF file, $1 \mathrm{MB}$.

FIG S5, TIF file, 0.8 MB.

FIG S6, TIF file, 0.7 MB.

TABLE S1, DOCX file, 0.01 MB.

\section{ACKNOWLEDGMENTS}

We are grateful to Lei Zhang and Ding Gao of the Core Facility and Technical Support at the Wuhan Institute of Virology, CAS, for their help with next-generation sequencing and confocal microscopy. We also thank Juan Min for her assistance with A549-ACE2 cell line sorting process.

This work was supported by the Ministry of Science and Technology (grant no. 2020 YFC0845800 and 2020YFC0842500 to W.G.), the Chinese Academy of Sciences (grant no. 2020 YJFK0107 to W.G.), and the Chinese Academy of Engineering (grant no. 2020-ZD-15 to W.G.). The funders had no role in the design, interpretation, or submission of this work for publication. Funding for open access charge came from the Chinese Academy of Sciences (grant no. 2020YJFK0107).

We declare no conflicts of interest.

\section{REFERENCES}

1. Li Q, Guan X, Wu P, Wang X, Zhou L, Tong Y, Ren R, Leung KSM, Lau EHY, Wong JY, Xing X, Xiang N, Wu Y, Li C, Chen Q, Li D, Liu T, Zhao J, Liu M, Tu W, Chen C, Jin L, Yang R, Wang Q, Zhou S, Wang R, Liu H, Luo Y, Liu Y, Shao G, Li H, Tao Z, Yang Y, Deng Z, Liu B, Ma Z, Zhang Y, Shi G, Lam TTY, Wu JT, Gao GF, Cowling BJ, Yang B, Leung GM, Feng Z. 2020. Early transmission dynamics in Wuhan, China, of novel coronavirusinfected pneumonia. N Engl J Med 382:1199-1207. https://doi.org/10 .1056/NEJMoa2001316.

2. Guo YR, Cao QD, Hong ZS, Tan YY, Chen SD, Jin HJ, Tan KS, Wang DY, Yan Y. 2020. The origin, transmission and clinical therapies on coronavirus disease 2019 (COVID-19) outbreak: an update on the status. Mil Med Res 7:11. https://doi.org/10.1186/s40779-020-00240-0.

3. Tian X, Li C, Huang A, Xia S, Lu S, Shi Z, Lu L, Jiang S, Yang Z, Wu Y, Ying T. 2020. Potent binding of 2019 novel coronavirus spike protein by a SARS coronavirus-specific human monoclonal antibody. Emerg Microbes Infect 9:382-385. https://doi.org/10.1080/22221751.2020.1729069.

4. Zhang $X Y$, Huang $\mathrm{HJ}$, Zhuang DL, Nasser MI, Yang MH, Zhu P, Zhao MY 2020. Biological, clinical and epidemiological features of COVID-19, SARS and MERS and AutoDock simulation of ACE2. Infect Dis Poverty 9:99. https://doi.org/10.1186/s40249-020-00691-6. 
5. Kennedy EM, Courtney DG, Tsai K, Cullen BR. 2017. Viral epitranscriptomics. J Virol 91. https://doi.org/10.1128/JVI.02263-16.

6. Tan B, Gao SJ. 2018. RNA epitranscriptomics: regulation of infection of RNA and DNA viruses by N(6) -methyladenosine (m(6) A). Rev Med Virol 28:e1983. https://doi.org/10.1002/rmv.1983.

7. Tan B, Gao SJ. 2018. The RNA epitranscriptome of DNA viruses. J Virol 92: e00696-18. https://doi.org/10.1128/JVI.00696-18.

8. Courtney DG, Tsai K, Bogerd HP, Kennedy EM, Law BA, Emery A, Swanstrom R, Holley CL, Cullen BR. 2019. Epitranscriptomic addition of $\mathrm{m}(5) \mathrm{C}$ to HIV-1 transcripts regulates viral gene expression. Cell Host Microbe 26:217-227.e6. https://doi.org/10.1016/j.chom.2019.07.005.

9. Tsai K, Cullen BR. 2020. Epigenetic and epitranscriptomic regulation of viral replication. Nat Rev Microbiol 18:559-570. https://doi.org/10.1038/ s41579-020-0382-3.

10. Tsai K, Jaguva Vasudevan AA, Martinez Campos C, Emery A, Swanstrom R, Cullen BR. 2020. Acetylation of cytidine residues boosts HIV-1 gene expression by increasing viral RNA stability. Cell Host Microbe 28:306-312.e6. https://doi.org/10.1016/j.chom.2020.05.011.

11. Yang Y, Sun BF, Xiao W, Yang X, Sun HY, Zhao YL, Yang YG. 2015. Dynamic $\mathrm{m}(6) \mathrm{A}$ modification and its emerging regulatory role in mRNA splicing. Sci Bull 60:21-32. https://doi.org/10.1007/s11434-014-0695-6.

12. Fu Y, Dominissini D, Rechavi G, He C. 2014. Gene expression regulation mediated through reversible m(6)A RNA methylation. Nat Rev Genet 15:293-306. https://doi.org/10.1038/nrg3724.

13. Agarwala SD, Blitzblau HG, Hochwagen A, Fink GR. 2012. RNA methylation by the MIS complex regulates a cell fate decision in yeast. PLoS Genet 8:e1002732. https://doi.org/10.1371/journal.pgen.1002732.

14. Dominissini D, Moshitch-Moshkovitz S, Schwartz S, Salmon-Divon M, Ungar L, Osenberg S, Cesarkas K, Jacob-Hirsch J, Amariglio N, Kupiec M, Sorek R, Rechavi G. 2012. Topology of the human and mouse m6A RNA methylomes revealed by m6A-seq. Nature 485:201-206. https://doi.org/ 10.1038/nature11112.

15. Horiuchi K, Kawamura T, Iwanari $H$, Ohashi R, Naito M, Kodama T, Hamakubo T. 2013. Identification of Wilms' tumor 1-associating protein complex and its role in alternative splicing and the cell cycle. J Biol Chem 288:33292-33302. https://doi.org/10.1074/jbc.M113.500397.

16. Liu J, Yue Y, Han D, Wang X, Fu Y, Zhang L, Jia G, Yu M, Lu Z, Deng X, Dai Q, Chen W, He C. 2014. A METTL3-METTL14 complex mediates mammalian nuclear RNA N6-adenosine methylation. Nat Chem Biol 10:93-95. https://doi.org/10.1038/nchembio.1432.

17. Meyer KD, Saletore Y, Zumbo P, Elemento O, Mason CE, Jaffrey SR. 2012. Comprehensive analysis of mRNA methylation reveals enrichment in $3^{\prime}$ UTRs and near stop codons. Cell 149:1635-1646. https://doi.org/10.1016/j .cell.2012.05.003.

18. Patil DP, Chen CK, Pickering BF, Chow A, Jackson C, Guttman M, Jaffrey SR. 2016. m(6)A RNA methylation promotes XIST-mediated transcriptional repression. Nature 537:369-373. https://doi.org/10.1038/nature19342.

19. Ping XL, Sun BF, Wang L, Xiao W, Yang X, Wang WJ, Adhikari S, Shi Y, Lv Y, Chen YS, Zhao X, Li A, Yang Y, Dahal U, Lou XM, Liu X, Huang J, Yuan WP, Zhu XF, Cheng T, Zhao YL, Wang X, Rendtlew Danielsen JM, Liu F, Yang YG. 2014. Mammalian WTAP is a regulatory subunit of the RNA N6-methyladenosine methyltransferase. Cell Res 24:177-189. https://doi.org/10 .1038/cr.2014.3.

20. Schwartz S, Mumbach MR, Jovanovic M, Wang T, Maciag K, Bushkin GG, Mertins P, Ter-Ovanesyan D, Habib N, Cacchiarelli D, Sanjana NE, Freinkman E, Pacold ME, Satija R, Mikkelsen TS, Hacohen N, Zhang F, Carr SA, Lander ES, Regev A. 2014. Perturbation of m6A writers reveals two distinct classes of mRNA methylation at internal and $5^{\prime}$ sites. Cell Rep 8:284-296. https://doi.org/10.1016/j.celrep.2014.05.048.

21. Zhong S, Li H, Bodi Z, Button J, Vespa L, Herzog M, Fray RG. 2008. MTA is an Arabidopsis messenger RNA adenosine methylase and interacts with a homolog of a sex-specific splicing factor. Plant Cell 20:1278-1288. https:// doi.org/10.1105/tpc.108.058883.

22. Lewis CJ, Pan T, Kalsotra A. 2017. RNA modifications and structures cooperate to guide RNA-protein interactions. Nat Rev Mol Cell Biol 18:202-210. https://doi.org/10.1038/nrm.2016.163.

23. Zhao BS, Roundtree IA, He C. 2017. Post-transcriptional gene regulation by mRNA modifications. Nat Rev Mol Cell Biol 18:31-42. https://doi.org/ 10.1038/nrm.2016.132.

24. Jia G, Fu Y, Zhao X, Dai Q, Zheng G, Yang Y, Yi C, Lindahl T, Pan T, Yang YG, He C. 2011. N6-methyladenosine in nuclear RNA is a major substrate of the obesity-associated FTO. Nat Chem Biol 7:885-887. https://doi.org/ 10.1038/nchembio.687.
25. Zheng G, Dahl JA, Niu Y, Fedorcsak P, Huang CM, Li CJ, Vagbo CB, Shi $Y$, Wang WL, Song SH, Lu Z, Bosmans RP, Dai Q, Hao YJ, Yang X, Zhao WM, Tong WM, Wang XJ, Bogdan F, Furu K, Fu Y, Jia G, Zhao X, Liu J, Krokan HE, Klungland A, Yang YG, He C. 2013. ALKBH5 is a mammalian RNA demethylase that impacts RNA metabolism and mouse fertility. Mol Cell 49:18-29. https://doi.org/10.1016/j.moslcel.2012.10.015.

26. Geula S, Moshitch-Moshkovitz S, Dominissini D, Mansour AA, Kol N, Salmon-Divon M, Hershkovitz V, Peer E, Mor N, Manor YS, Ben-Haim MS, Eyal E, Yunger S, Pinto Y, Jaitin DA, Viukov S, Rais Y, Krupalnik V, Chomsky E, Zerbib M, Maza I, Rechavi Y, Massarwa R, Hanna S, Amit I, Levanon EY, Amariglio N, Stern-Ginossar N, Novershtern N, Rechavi G, Hanna JH. 2015. m6A mRNA methylation facilitates resolution of naive pluripotency toward differentiation. Science 347:1002-1006. https://doi.org/10.1126/ science.1261417.

27. Wang X, Lu Z, Gomez A, Hon GC, Yue Y, Han D, Fu Y, Parisien M, Dai Q, Jia G, Ren B, Pan T, He C. 2014. N6-methyladenosine-dependent regulation of messenger RNA stability. Nature 505:117-120. https://doi.org/10.1038/ nature 12730 .

28. Xu C, Wang X, Liu K, Roundtree IA, Tempel W, Li Y, Lu Z, He C, Min J. 2014. Structural basis for selective binding of m6A RNA by the YTHDC1 YTH domain. Nat Chem Biol 10:927-929. https://doi.org/10.1038/nchembio .1654 .

29. Liu N, Dai Q, Zheng G, He C, Parisien M, Pan T. 2015. N(6)-methyladenosine-dependent RNA structural switches regulate RNA-protein interactions. Nature 518:560-564. https://doi.org/10.1038/nature14234.

30. Meyer KD, Patil DP, Zhou J, Zinoviev A, Skabkin MA, Elemento O, Pestova TV, Qian SB, Jaffrey SR. 2015. 5' UTR m(6)A promotes cap-independent translation. Cell 163:999-1010. https://doi.org/10.1016/j.cell.2015.10.012.

31. Wang X, Zhao BS, Roundtree IA, Lu Z, Han D, Ma H, Weng X, Chen K, Shi H, He C. 2015. N(6)-methyladenosine modulates messenger RNA translation efficiency. Cell 161:1388-1399. https://doi.org/10.1016/j.cell.2015.05.014.

32. Banerjee AK. 1980. $5^{\prime}$-Terminal cap structure in eucaryotic messenger ribonucleic acids. Microbiol Rev 44:175-205. https://doi.org/10.1128/mr.44.2.175 $-205.1980$.

33. Boone RF, Moss B. 1977. Methylated 5'-terminal sequences of vaccinia virus mRNA species made in vivo at early and late times after infection. Virology 79:67-80. https://doi.org/10.1016/0042-6822(77)90335-x.

34. Both GW, Banerjee AK, Shatkin AJ. 1975. Methylation-dependent translation of viral messenger RNAs in vitro. Proc Natl Acad Sci U S A 72:1189-1193. https://doi.org/10.1073/pnas.72.3.1189.

35. Furuichi Y, Morgan M, Muthukrishnan S, Shatkin AJ. 1975. Reovirus messenger RNA contains a methylated, blocked $5^{\prime}$-terminal structure: $\mathrm{m}-7 \mathrm{G}\left(5^{\prime}\right)$ ppp(5')G-MpCp. Proc Natl Acad Sci U S A 72:362-366. https://doi.org/10 .1073/pnas.72.1.362.

36. Moyer SA, Banerjee AK. 1976. In vivo methylation of vesicular stomatitis virus and its host-cell messenger RNA species. Virology 70:339-351. https://doi.org/10.1016/0042-6822(76)90276-2.

37. Gokhale NS, McIntyre AB, McFadden MJ, Roder AE, Kennedy EM, Gandara JA, Hopcraft SE, Quicke KM, Vazquez C, Willer J, Ilkayeva OR, Law BA, Holley CL, Garcia-Blanco MA, Evans MJ, Suthar MS, Bradrick SS, Mason CE, Horner SM. 2016. N6-methyladenosine in Flaviviridae viral RNA genomes regulates infection. Cell Host Microbe 20:654-665. https://doi.org/10 .1016/j.chom.2016.09.015.

38. Lichinchi G, Zhao BS, Wu Y, Lu Z, Qin Y, He C, Rana TM. 2016. Dynamics of human and viral RNA methylation during Zika virus infection. Cell Host Microbe 20:666-673. https://doi.org/10.1016/j.chom.2016.10.002.

39. Kennedy EM, Bogerd HP, Kornepati AV, Kang D, Ghoshal D, Marshall JB, Poling BC, Tsai K, Gokhale NS, Horner SM, Cullen BR. 2016. Posttranscriptional m(6)A editing of HIV-1 mRNAs enhances viral gene expression. Cell Host Microbe 19:675-685. https://doi.org/10.1016/j.chom.2016.04.002.

40. Lichinchi G, Gao S, Saletore Y, Gonzalez GM, Bansal V, Wang Y, Mason CE, Rana TM. 2016. Dynamics of the human and viral m(6)A RNA methylomes during HIV-1 infection of T cells. Nat Microbiol 1:16011. https://doi.org/10 .1038/nmicrobiol.2016.11.

41. Tirumuru N, Zhao BS, Lu W, Lu Z, He C, Wu L. 2016. N(6)-methyladenosine of HIV-1 RNA regulates viral infection and HIV-1 Gag protein expression. Elife 5:e15528. https://doi.org/10.7554/eLife.15528.

42. Courtney DG, Kennedy EM, Dumm RE, Bogerd HP, Tsai K, Heaton NS, Cullen BR. 2017. Epitranscriptomic enhancement of influenza $A$ virus gene expression and replication. Cell Host Microbe 22:377-386.e5. https://doi.org/10 .1016/j.chom.2017.08.004.

43. Tsai K, Courtney DG, Cullen BR. 2018. Addition of m6A to SV40 late mRNAs enhances viral structural gene expression and replication. PLoS Pathog 14:e1006919. https://doi.org/10.1371/journal.ppat.1006919. 
44. Tan B, Liu H, Zhang S, da Silva SR, Zhang L, Meng J, Cui X, Yuan H, Sorel O, Zhang SW, Huang Y, Gao SJ. 2018. Viral and cellular N(6)-methyladenosine and N(6), $2^{\prime}$-O-dimethyladenosine epitranscriptomes in the KSHV life cycle. Nat Microbiol 3:108-120. https://doi.org/10.1038/s41564-017-0056-8.

45. Hesser CR, Karijolich J, Dominissini D, He C, Glaunsinger BA. 2018. N6methyladenosine modification and the YTHDF2 reader protein play cell type specific roles in lytic viral gene expression during Kaposi's sarcomaassociated herpesvirus infection. PLoS Pathog 14:e1006995. https://doi .org/10.1371/journal.ppat.1006995.

46. Ye F, Chen ER, Nilsen TW. 2017. Kaposi's sarcoma-associated herpesvirus utilizes and manipulates RNA N(6)-adenosine methylation to promote lytic replication. J Virol 91:e00466-17. https://doi.org/10.1128/JVI.00466-17.

47. Liu J, Xu YP, Li K, Ye Q, Zhou HY, Sun H, Li X, Yu L, Deng YQ, Li RT, Cheng ML, He B, Zhou J, Li XF, Wu A, Yi C, Qin CF. 2021. The m(6)A methylome of SARS-CoV-2 in host cells. Cell Res 31:404-414. https://doi.org/10.1038/ s41422-020-00465-7.

48. Jin $X$, Lian JS, Hu JH, Gao J, Zheng L, Zhang YM, Hao SR, Jia HY, Cai H, Zhang XL, Yu GD, Xu KJ, Wang XY, Gu JQ, Zhang SY, Ye CY, Jin CL, Lu YF, Yu X, Yu XP, Huang JR, Xu KL, Ni Q, Yu CB, Zhu B, Li YT, Liu J, Zhao H, Zhang X, Yu L, Guo YZ, Su JW, Tao JJ, Lang GJ, Wu XX, Wu WR, Qv TT, Xiang DR, Yi P, Shi D, Chen Y, Ren Y, Qiu YQ, Li LJ, Sheng J, Yang Y. 2020. Epidemiological, clinical and virological characteristics of 74 cases of coronavirus-infected disease 2019 (COVID-19) with gastrointestinal symptoms. Gut 69:1002-1009. https://doi.org/10.1136/gutjnl-2020-320926.

49. Kim D, Lee JY, Yang JS, Kim JW, Kim VN, Chang H. 2020. The architecture of SARS-CoV-2 transcriptome. Cell 181:914-921.e10. https://doi.org/10 .1016/j.cell.2020.04.011.

50. Hao H, Hao S, Chen H, Chen Z, Zhang Y, Wang J, Wang H, Zhang B, Qiu J, Deng F, Guan W. 2019. N6-methyladenosine modification and METTL3 modulate enterovirus 71 replication. Nucleic Acids Res 47:362-374. https://doi.org/10.1093/nar/gky1007.

51. Yao M, Dong Y, Wang Y, Liu H, Ma H, Zhang H, Zhang L, Cheng L, Lv X, Xu Z, Zhang F, Lei Y, Ye W. 2020. N(6)-methyladenosine modifications enhance enterovirus 71 ORF translation through METTL3 cytoplasmic distribution. Biochem Biophys Res Commun 527:297-304. https://doi.org/10 .1016/j.bbrc.2020.04.088.

52. Chen J, Jin L, Wang Z, Wang L, Chen Q, Cui Y, Liu G. 2020. N6-methyladenosine regulates PEDV replication and host gene expression. Virology 548:59-72. https://doi.org/10.1016/j.virol.2020.06.008.

53. Lu W, Tirumuru N, St Gelais C, Koneru PC, Liu C, Kvaratskhelia M, He C, Wu L. 2018. N(6)-methyladenosine-binding proteins suppress HIV-1 infectivity and viral production. J Biol Chem 293:12992-13005. https://doi.org/10 $.1074 /$ jbc.RA118.004215.

54. Gokhale NS, Horner SM. 2017. RNA modifications go viral. PLoS Pathog 13:e1006188. https://doi.org/10.1371/journal.ppat.1006188.

55. Kim GW, Imam H, Khan M, Siddiqui A. 2020. N(6)-methyladenosine modification of hepatitis $B$ and $C$ viral RNAs attenuates host innate immunity via RIG-I signaling. J Biol Chem 295:13123-13133. https://doi.org/10 $.1074 /$ jbc.RA120.014260.

56. Li N, Hui H, Bray B, Gonzalez GM, Zeller M, Anderson KG, Knight R, Smith D, Wang Y, Carlin AF, Rana TM. 2021. METTL3 regulates viral m6A RNA modification and host cell innate immune responses during SARS-CoV-2 infection. Cell Rep 35:109091. https://doi.org/10.1016/j.celrep.2021.109091.
57. Lu M, Zhang Z, Xue M, Zhao BS, Harder O, Li A, Liang X, Gao TZ, Xu Y, Zhou J, Feng Z, Niewiesk S, Peeples ME, He C, Li J. 2020. N(6)-methyladenosine modification enables viral RNA to escape recognition by RNA sensor RIG-I. Nat Microbiol 5:584-598. https://doi.org/10.1038/s41564-019 -0653-9.

58. Meyer KD, Jaffrey SR. 2014. The dynamic epitranscriptome: N6-methyladenosine and gene expression control. Nat Rev Mol Cell Biol 15:313-326. https://doi.org/10.1038/nrm3785.

59. Ogando NS, Zevenhoven-Dobbe JC, van der Meer Y, Bredenbeek PJ, Posthuma CC, Snijder EJ. 2020. The enzymatic activity of the nsp14 exoribonuclease is critical for replication of MERS-CoV and SARS-CoV-2. J Virol 94:e01246-20. https://doi.org/10.1128/JVI.01246-20.

60. Liu C, Zhu X, Lu Y, Zhang X, Jia X, Yang T. 2020. Potential treatment of Chinese and western medicine targeting Nsp14 of SARS-CoV-2. J Pharm Anal https://doi.org/10.1016/j.jpha.2020.08.002.

61. Vijayan V, Pant P, Vikram N, Kaur P, Singh TP, Sharma S, Sharma P. 2020. Identification of promising drug candidates against NSP16 of SARS-CoV-2 through computational drug repurposing study. J Biomol Struct Dyn https://doi.org/0.1080/07391102.2020.1802349:1-15.

62. Du Y, Hou G, Zhang H, Dou J, He J, Guo Y, Li L, Chen R, Wang Y, Deng R, Huang J, Jiang B, Xu M, Cheng J, Chen GQ, Zhao X, Yu J. 2018. SUMOylation of the m6A-RNA methyltransferase METTL3 modulates its function. Nucleic Acids Res 46:5195-5208. https://doi.org/10.1093/nar/gky156.

63. Chen H, Pei R, Zhu W, Zeng R, Wang Y, Wang Y, Lu M, Chen X. 2014. An alternative splicing isoform of MITA antagonizes MITA-mediated induction of type I IFNs. J Immunol 192:1162-1170. https://doi.org/10.4049/jimmunol .1300798 .

64. Chen S, Zhou Y, Chen Y, Gu J. 2018. fastp: an ultra-fast all-in-one FASTQ preprocessor. Bioinformatics 34:i884-i890. https://doi.org/10.1093/bioinformatics/ bty560.

65. Kim D, Langmead B, Salzberg SL. 2015. HISAT: a fast spliced aligner with low memory requirements. Nat Methods 12:357-360. https://doi.org/10 .1038/nmeth.3317.

66. Ramirez F, Ryan DP, Gruning B, Bhardwaj V, Kilpert F, Richter AS, Heyne S, Dundar F, Manke T. 2016. deepTools2: a next generation web server for deep-sequencing data analysis. Nucleic Acids Res 44:W160-W165. https://doi.org/10.1093/nar/gkw257.

67. Zhang Y, Liu T, Meyer CA, Eeckhoute J, Johnson DS, Bernstein BE, Nusbaum C, Myers RM, Brown M, Li W, Liu XS. 2008. Model-based analysis of ChIP-Seq (MACS). Genome Biol 9:R137. https://doi.org/10.1186/gb -2008-9-9-r137.

68. Lorenz DA, Sathe S, Einstein JM, Yeo GW. 2020. Direct RNA sequencing enables $\mathrm{m}(6)$ A detection in endogenous transcript isoforms at base-specific resolution. RNA 26:19-28. https://doi.org/10.1261/rna.072785.119.

69. Stoiber M, Quick J, Egan R, Lee JE, Celniker S, Neely RK, Loman N, Pennacchio LA, Brown J. 2017. De novo identification of DNA modifications enabled by genome-guided nanopore signal processing. bioRxiv https://doi.org/https://doi.org/10.1101/094672.

70. Wagih O. 2017. ggseqlogo: a versatile $R$ package for drawing sequence logos. Bioinformatics 33:3645-3647. https://doi.org/10.1093/bioinformatics/btx469.

71. Liu Y, Zheng Z, Shu B, Meng J, Zhang Y, Zheng C, Ke X, Gong P, Hu Q, Wang H. 2016. SUMO modification stabilizes enterovirus 71 polymerase 3D to facilitate viral replication. J Virol 90:10472-10485. https://doi.org/10 .1128/JVI.01756-16. 